\title{
La integración del derecho de los consumidores al Código Civil ${ }^{*}$
}

Pietro Sirena**

\section{La regulación de los contratos celebrados por los consumidores: de la fragmentariedad inorgánica a la integración en el derecho común de los contratos}

El derecho de los contratos celebrados por los consumidores ha hecho su entrada en el ordenamiento jurídico italiano como consecuencia de la aplicación de algunas directivas comunitarias emitidas a partir de la mitad del decenio 1980-1990. ${ }^{1}$ El origen comunitario europeo de estos regímenes jurídicos es de fundamental importancia no solo para interpretar los documentos legislativos nacionales que las han dictado, sino también, y sobre todo, para explicar su fundamento y su razón sustancial. ${ }^{2}$

El presente ensayo se basa en la ponencia "Contratos estipulados con los consumidores: conveniencia o inconveniencia de su regulación en el Código Civil», expuesta en el congreso "El Código Civil del 1984: veinte años de vigencia. Pasado y futuro», Ilevado a cabo por la Pontificia Universidad Católica del Perú, Lima, 8-12 noviembre de 2004, por invitación del profesor Gastón Fernandez Cruz.

Traducción de Leysser L. León. Profesor de Derecho Civil de la Pontificia Universidad Católica del Perú. Diplomado en Lengua y Cultura Italianas por la Università per Stranieri di Perugia (Italia).

** Profesor ordinario de Instituciones de Derecho Privado y de Derecho Privado Europeo en la Università degli Studi di Siena.

1 Un comentario tan esencial cuanto valioso de cada una de aquellas Directivas se puede leer en GRUNDMANN, S. Europäisches Schuldvertragsrecht. Das europäische Recht der Unternehmensgeschäfte. Berlín, Nueva York, 1999.

2 BENEDETTI, G. "Tutela del consumatore e autonomia contrattuale». En G. Vettori (ed.). Materiali e commenti sul nuovo diritto dei contratti. Padua, 1999, p. 801, quien destaca que la incidencia del derecho comunitario no determina solamente la mutación de normas jurídicas específicas, sino, "con una decidida mutación de perspectiva, la ampliación 
Dicha peculiaridad ha influido grandemente, por lo demás, en la técnica legislativa empleada por el legislador italiano, tal cual puede percibirse a partir de la lectura misma de las disposiciones respectivas: el sentido de ellas tiende, en efecto, a repetir al pie de la letra, aun cuando no en todos los casos, el de las directivas que correspondía aplicar. ${ }^{3}$ Sin embargo, y más allá de los defectos de estilo -imputables, en principio, a cierta superficialidad del legislador italiano, antes que a la forzada carencia de tecnicidad del legislador comunitario—- ${ }^{4}$ lo que se señala explica por qué, desde el punto de vista de las fuentes del derecho, las regulaciones jurídicas ahora examinadas han sido adoptadas, salvo raras excepciones, ${ }^{5}$ mediante otras tantas leyes especiales, extrañas al Código Civil. ${ }^{6}$ Se trata de una sucesión de dispositivos que el legislador ha emanado "día tras día", casi siempre limitándose a reproducir las directivas comunitarias y, en todo caso, sin realizar

del horizonte hermenéutico mismo». Por lo tanto, todo esfuerzo de construcción del derecho privado europeo, antes que ser una actualización de las reglas jurídicas aplicables a específicos sectores o instituciones, presupone que las categorías conceptuales de la tradición civilística sean adaptadas, desde el interior, frente a la irrupción del derecho comunitario (así: LIPARI, N. «Introduzione». En su edición de Trattato di diritto privato europeo. 2. ${ }^{a}$ ed. Vol. I. Padua, 2003, p. 1 y ss., seguido por MACARIO, F. "I diritti oltre la legge. Principi e regole nel nuovo diritto dei contratti». En Scritti in onore di Pietro Rescigno. T. III-2. Milán, 1998, p. 483 y ss.).

Justamente porque no se trata de una simple modificación de los datos del derecho positivo, sino del remecimiento de la "apertura original» con la que ellos han sido percibidos y formalizados en su conjunto, se advierte, en el cuadro descrito, el desafío inédito y fascinante que se plantea hoy para la ciencia jurídica. Esta demanda de renovación ha recibido en LIPARI, N. (ed.). Trattato di diritto privato europeo. 4 volúmenes. Padua, 2003; y ya en la obra precedente, a cargo del mismo autor, Diritto privato europeo. 2 vols. Padua, 1997, no solo su más consciente planteamiento metodológico (véase la antes citada Introduzione de Lipari), sino también su primera realización orgánica.

3 Véase, por todos, Nova, G. de. "Dieci "voci" per una tavola rotonda su "ll nuovo diritto dei contratti"». En Materiali e commenti sul nuovo diritto dei contratti. Op. cit., p. 814 y ss.

4 En la desdeñosa crítica de FLUME, W. "Vom Beruf unserer Zeit für Gesetzgebung». Zeitschrift für Wirtschaftsrecht, 2000, p. 1427 y ss., la acusación de desfiguración del «monumento cultural» (Kulturdenkmal) del Bürgerliches Gesetzbuch (BGB) con la aplicación de las directivas comunitarias es dirigida, justamente, contra el legislador alemán, no sin dejar en claro que no se puede considerar responsable de ello al legislador comunitario.

5 Nos referimos a la regulación de las «cláusulas vejatorias en el contrato entre comerciante profesional y consumidor» (arts. 1469-bis y ss. del Código Civil, en aplicación de la directiva 93/13/CEE) y a la regulación de la "venta de los bienes de consumo» (arts. 1519-bis y ss. del Código Civil, en aplicación de la directiva 1999/44/CE).

6 Para un análisis detallado, véase AMATO, C. Per un diritto europeo dei contratti con i consumatori. Problemi e tecniche di attuazione della legislazione comunitaria nell'ordinamento italiano e nel Regno Unito. Milán, 2003, p. 71 y ss. 
ningún esfuerzo de coordinación ni de integración efectiva de la realidad normativa preexistente. ${ }^{7}$

Sin perjuicio de lo anterior, no puede sostenerse que, fuera de la exigencia práctica de aplicar las directivas en un plazo breve (no siempre respetado, dicho sea de paso), el modus operandi haya sido inconveniente en absoluto, porque el nuevo derecho de los contratos que se iba perfilando en el horizonte parecía «monstruoso», si se le comparaba con el ordenamiento jurídico nacional, y, es más, potencialmente abolitivo de algunos de sus principios generales. ${ }^{8}$ Por ello, el dejar que tal derecho se mantuviera fragmentado y disperso en una gran cantidad de disposiciones episódicas, cada cual caracterizada por una extrema especificidad, constituía (no solamente la opción más cómoda, sino también) una justa cautela, idónea para permitir una primera experimentación, jurisprudencial y doctrinal a la vez, de las reglas aquí estudiadas, con una circunscripción al mínimo de su relevancia sistemática. Lo anterior era válido, con mayor razón, si se considera que el derecho comunitario europeo de los contratos, a pesar de no estar privado, para nada, de una propia y rigurosa coherencia interna, ${ }^{9}$ no se ha desarrollado según un proyecto orgánico predeterminado, sino sobre la base de un método esencialmente empírico, cuando menos en la determinación de las materias que regula. ${ }^{10}$ Así las cosas, no podía predecirse hasta qué punto iba a extenderse la armonización de los ordenamientos jurídicos nacionales ni con cuánta intensidad. Solo hoy en día, con el impulso de una importante Comunicación de la Comisión Europea, del 2001, ${ }^{11}$ ha comenzado una discusión significativa al respecto. ${ }^{12}$

Véase, por todos, Nova, G. de. "Contratto: per una voce». Rivista di diritto privato, 2000, p. 635.

8 Sobre este último, véase, por todos, MACARIO, F. «Alla ricerca dei «principi comuni» per l'armonizzazione del diritto europeo dei contratti». En F. Cafaggi. Quale armonizzazione per il diritto europeo dei contratti? Padua, 2003, p. 30.

9 Véase, al respecto, GRUNDMANN, S. "La struttura del diritto europeo dei contratti». Trad. de Pietro Sirena. Rivista di diritto civile, 2002, I, p. 365 y ss.

10 Véase, por todos, GANDOLFI, G. «Per l'assetto normativo del mercato interno europeo: proposte e prospettive». Rivista di diritto civile, 2003, I, p. 400 y ss.

1 Comunicación de la Comisión al Consejo y al Parlamento Europeo sobre el derecho contractual europeo, del 11 de julio del 2001, COM(2001) 398 def. Entre los primeros comentarios de este documento, véase ALPA, G. "La comunicazione n. 398/2001/CE sulla armonizzazione del diritto privato. Una premessa al dibattito». La Nuova giurisprudenza civile commentata, 2001, II, p. 425 y ss.; BAR, C. von. "Die Mitteilung der Europäischen Kommission zum Europäischen Vertragsrecht». Zeitschrift für europäisches Privatrecht, 2001, p. 799 y ss.

12 Las opiniones que instituciones, estudiosos del derecho y operadores económicos han dirigido a la Comisión están resumidas en una reseña oficial, que puede consultarse en 
La aplicación "puntual» de las directivas comunitarias en la materia que venimos tratando fue, entonces, una decisión sensata, si cabe utilizar el término sensatez. Con todo, ella resulta absolutamente perjudicial para la eficiencia del ordenamiento jurídico, al haber desaparecido las razones que, en un principio, le dieron justificación. ${ }^{13}$

En primer lugar, la impresión de que las reglas en cuestión se limitan a dar una respuesta inmediata a algunos problemas contingentes, en lugar de constituir las piezas de un diseño de política del derecho orgánico y coherente, ha desincentivado un adecuado esfuerzo de racionalización por parte de la doctrina civilista en su conjunto. La bibliografía especializada, si se prescinde de algunos estudios excepcionalmente pioneros, ${ }^{14}$ está constituida por minuciosos y exegéticos comentarios a diversas disposiciones, comentarios dirigidos, en general, a una primera lectura de estas. Y, cuando la jurisprudencia es copiosa y relevante —en el tema de las cláusulas abusivas (arts. 1469-bis y ss. del Código Civil, por ejemplo)—, abundan los comentarios de sentencias de tono periodístico. Desde luego, dichos géneros de la literatura jurídica no son, en modo alguno, secundarios, solo que es difícil que, con ellos, se dé pleno cumplimiento a la tarea de la doctrina en relación con un fenómeno jurídico que - como alguien ha anotado- ${ }^{15}$ debe considerarse entre los más imponentes y significativos de los últimos tiempos.

Por otro lado, la especificidad de la materia regulada por cada disposición, vista aisladamente, ha hecho que la mayor parte del derecho de los contratos celebrados por los consumidores - con la sola excepción de la regulación de las cláusulas abusivas y de la regulación de la venta de bienes de consumo- ${ }^{16}$ se considere prácticamente marginal y poco significativa no solo en relación con los fenómenos socioeconómicos actuales, sino también con el ordenamien-

<http://europa.eu.int/comm/consumers/cons_int/safe_shop/fair_bus_pract/cont_law/comments/summaries/sum_it.pdfs. La opinión conjunta de la Commission on European Contract Law y del Study Group on a European Civil Code también puede leerse en LANDO, O. y C. von BAR. La nuova giurisprudenza civile commentata, 2001, II, p. 598 y ss. Véase, también, infra, n. ${ }^{\circ} 7$.

13 Roth, W. H. "Transposing "Pointillist" EC Guidelines into Systematic National Codes Problems and Consequences». European Review of Private Law, 2002, p. 761 y ss.

${ }_{14}$ No se puede evitar recordar, entre estos, el volumen de ALPA, G. Tutela del consumatore e controlli sull'impresa. Bolonia, 1978, al cual han subseguido id. Diritto privato dei consumi. Bolonia, 1986; e id. Il diritto dei consumatori. Roma, Bari, 2002.

15 PERLINGIERI, P. "Il nuovo diritto dei contratti fra persona e mercato». En Materiali e commenti sul nuovo diritto dei contratti. Op. cit., p. 827; ROPPO, V. II contratto del duemila. Turín, 2002, p. 10 y ss.

16 La colocación de tales regulaciones en el Código no es extraña, ciertamente, a su relevancia aplicativa y sistemática, de la cual constituye, al mismo tiempo, una consecuencia y una causa (véase también lo que señalamos más adelante e infra, n. ${ }^{\circ}$ 7). 
to jurídico en su conjunto. La nueva realidad normativa a la que hacemos referencia ha sido generalmente subvaluada, por lo tanto, en la circulación de las ideas en el ámbito científico e incluso antes en el estudio institucional del derecho privado. En los tratados generales sobre contratos, se tiende a ignorarla o, a lo sumo, a brindar sucintas indicaciones sobre ella.

Respecto de las categorías conceptuales con las cuales la doctrina formaliza los datos del derecho positivo, dichos fenómenos parecen provocar una suerte de corto circuito. Mientras más se enfatiza el carácter fragmentario y marginal de las reglas que nos ocupan, mucho más se realza, paradójicamente, la autonomía normativa, y se tiende, es más, a identificar en ello una especie de derecho sectorial. Sin embargo, esta conclusión no hace otra cosa que agudizar la percepción de fragmentariedad y de marginalidad de tales regulaciones, como si ellas fueran "otra cosa», al margen de lo que el civilista está dispuesto a tomar seriamente en consideración y a visualizar como derecho del contrato. ${ }^{17}$

La tesis que pretendemos sostener en estas páginas, en cambio, es que las regulaciones sobre los contratos celebrados por los consumidores, o por lo menos parte de ellas, deberían integrarse, plenamente, a la parte general del contrato. ${ }^{18}$ Con esta última expresión, no se hace referencia a aquella sección del Código Civil que contiene las disposiciones relativas a los contratos en general —o sea, al título II del libro IV (art. 1321 y ss. del Código Civil italiano)-, sino, en sentido sustancial, al conjunto de las normas generales que, al margen de su colocación topográfica, «conforman, en su totalidad, el ordenamiento al que se encuentran sometidas las reglas particulares de los distintos tipos contractuales». ${ }^{19}$

17 Este punto es lúcidamente subrayado por WILHELMSON, T. "IS There a European Consumer Law - and Should There Be One?». Saggi, conferenze e seminari, n. ${ }^{\circ} 41$, Roma, Centro di studi e ricerche di diritto comparato e straniero (ed.). 2000, p. 5 y ss., quien considera que la "segregation of consumer law» constituiría una solución incongruente para el desarrollo del derecho privado, pues presupondría la conservación de la parte general del contrato y de los valores sociales que ella expresa. A fin de crear una evolución del ordenamiento jurídico «in a more welfaristic direction», el autor citado opina, de todas formas, que es necesario que la aplicación del derecho de los consumidores quede confiada a jueces especiales o a específicas autoridades independientes.

18 Al respecto, véase Nuzzo, $M$. "Tutela del consumatore e disciplina generale del contratto». En Materiali e commenti sul nuovo diritto dei contratti. Op. cit., p. 830 y ss.

19 BENEDETTI, G. Il diritto comune dei contratti e degli atti unilaterali. 2. ${ }^{a}$ ed. Nápoles, 1997, p. 69. La tesis, que ha encontrado, justamente, en la obra de este autor su mejor demostración, no ha estado libre de oposiciones, porque la doctrina del derecho civil ha puesto en duda, cada vez con mayor insistencia, el papel central de la parte general del contrato (véase, sobre todo, NovA, G. de. "Sul rapporto tra disciplina generale dei contratti e disciplina dei singoli contratti». Contratto e impresa, 1988, p. 327 y ss.; id. "I singoli contratti: dal titolo III del libro IV del codice civile alla disciplina attuale». En 
Según tal planteamiento, la específica colocación tipográfica de las disposiciones relativas a los contratos celebrados por los consumidores no descarta, de ningún modo, que las normas por ellas dictadas sean asimilables a la parte general del contrato; ${ }^{20}$ lo que se debe determinar, más bien, es si ellas, tomando en cuenta su razón justificativa y su fundamento, dan lugar a un derecho especial (Sonderrecht) o si introducen en el ordenamiento jurídico un nuevo núcleo de reglas y de principios generales, en el cual se pueda reconocer aquel intrínseco "valor axiológico y [aquella] fuerza expansiva» que —en palabras del estudioso que mejor ha captado su esencia $-{ }^{21}$ caracterizan, justamente, el derecho común de los contratos. En sentido inverso - y como veremos en su momento-, 22 es el resutado de dicha investigación, ni más ni menos, el que debe inducir a evaluar críticamente el estado actual de las fuentes del derecho, y a promover, por consiguiente, de iure condendo, la adaptación de su fenomenología a la realidad sustancial y, más aún, la recodificación de muchas de las reglas que habremos de considerar. ${ }^{23}$

Scritti in onore di Luigi Mengoni. I. Milán, 1995, p. 487 y ss.; VITUCCI, P. "Parte generale e parte speciale nella disciplina dei contratti». En la misma obra, p. 804 y ss.). Sin embargo, esta última tendencia es susceptible de una radical revisión crítica (véase MONATERI, P. G. "Ripensare il contratto: verso una visione antagonista del contratto». Rivista di diritto civile, 2003, I, p. 409 y ss., especialmente p. 416. Hay traducción al castellano de LEÓN, Leysser L. "Reformulando la noción de contrato: hacia una visión antagónica del contrato». Thémis, revista de derecho, $2 .^{a}$ época, n. ${ }^{\circ} 49,2004$, p. 37 y ss.). Incluso si se toma partido por las tesis más escépticas, según las cuales la (positividad de la) parte general del contrato no sería otra cosa que un mito, sigue siendo cierto que, justamente en cuanto tal, ella "n'a pas paru pouvoir être réduit à une légende, un conte, une histoire fausse», sino que "traduit en effet une mise en ordre de l'univers des juristes», lo cual es suficiente para legitimar la imposibilidad de sustituirla dogmáticamente (SAVAUX. La théorie générale du contrat, mythe ou réalité? París, 1997, p. 345).

20 BENEDETTI, G. Il diritto comune dei contratti e degli atti unilaterali. Op. cit., p. 54. Incluso en el ámbito de una orientación diversa de pensamiento, tendencialmente escéptico sobre el lugar central, conceptual y normativo, de la parte general del contrato, se ha destacado que el alcance aplicativo de las disposiciones relativas a los contratos en particular podría no estar circunscrita, en realidad, a la parte especial (VITUCCI, P. Op. cit., p. 809).

21 BENEDETTI, G. Il diritto comune dei contratti e degli atti unilaterali. Op. cit., p. 68.

22 Véase infra, $n .^{\circ} 7$

23 Esta demanda de reforma, que implica una nueva reflexión crítica no solo de la específica temática aquí considerada, sino también, con carácter más general, de la llamada «europeización» de los ordenamientos jurídicos, ya ha tenido acogida, históricamente, en la experiencia alemana, con la reciente "modernización del derecho de las obligaciones» (Schuldrechtsmodernisierung), que ha modificado de modo orgánico el BGB (véase PATTI, S. "I contratti del consumatore e la ricodificazione tedesca». Europa e diritto privato, 2003, p. 503 y ss.). Hay que subrayar, por otro lado, que ya en el año 2000 se había insertado en el BGB una expresa definición legislativa de "consumidor» (Verbraucher, § 13) y de comerciante profesional (Unternehmer, § 14), a fin de delimitar uniformemente el ámbito subjetivo de aplicación de las leyes especiales en materia 
La relación entre las reglas de los contratos celebrados por los consumidores y el derecho común de los contratos debe ser examinada, principalmente, en su aspecto axiológico, a fin de verificar si se trata de contextos normativos homogéneos desde el punto de vista de los intereses protegidos (y, por ende, de los valores respectivos); en particular, puesto que - como ya hemos destacado brevemente- la concepción corriente parecería conducir —si es desarrollada coherentemente- hacia conclusiones opuestas a las que aquí sostemenos, será conveniente establecer, en sentido negativo, que las reglas de los contratos celebrados por los consumidores no son, en realidad, axiológicamente incompatibles con el régimen general del contrato.

\section{El análisis funcional: el valor de la libertad de iniciativa económica privada}

El análisis que nos hemos propuesto efectuar debe centrarse, en primer lugar, en la relación que media entre el contrato y el mercado.

Hoy goza de difusión en la doctrina del derecho civil la idea de que el régimen general del contrato hace de este el instrumento para ejercer la "libertad del sujeto de realizar sus elecciones libremente en el mercado». ${ }^{24}$ En tal sentido, se ha destacado que las nociones de «contrato» y de «mercado»y, más aún, sus respectivas reglas jurídicas son indisolubles: ${ }^{25}$ en efecto, tales nociones se presentan en una relación de recíproca interdependencia, sobre cuya base la estipulación de los contratos es la que crea el mercado, ${ }^{26}$

(véase MICKLITZ, H. «La nozione di consumatore nel § 13 BGB». Rivista di diritto civile, 2001, I, p. 623 y ss.).

24 BIANCA, C. M. Diritto civile, III, Il contratto, 2. ${ }^{a}$ ed. Milán, 2000, p. 31 (nota 100). Es de recordar que, en el comentario bibliográfico, significativamente titulado "Contratto e mercato. A proposito del III volume de "Il diritto civile» di C. M. Bianca, Milano, Giuffrè, 1984» (originalmente publicado en Quadrimestre, 1985, y ahora en Scritti giuridici, VIII, Milán, 2001, p. 227 y ss.), T. Auletta identificaba la principal clave de lectura de dicha obra, justamente, en "la íntima interdependencia entre régimen del contrato y características del mercado".

25 BENEDETTI, G. II diritto comune dei contratti e degli atti unilaterali. Op. cit., especialmente p. 154 y ss. Es significativo que coincidan sobre este punto, a pesar de partir de posiciones principistas claramente diversas, los ensayos de SCHLESINGER, $P$. "L'autonomia privata e i suoi limiti». Giurisprudeza italiana, 1999, p. 230; y de PERLINGIERI, P. "Nuovi profili del contratto». Rivista critica del diritto privato, 2001, p. 225 y ss. Para ulteriores indicaciones bibliográficas, véase GuIzzı, G. "Mercato concorrenziale e teoria del contratto». Rivista del diritto commerciale e del diritto generale delle obbligazioni, 1999, I, p. 67 y ss.

26 ANGELICI, C. Diritto Commerciale. I. Roma, Bari, 2002, p. 3. 
mientras que, paralelamente, es este el que hace posible el ejercicio de la autonomía negocial de los particulares. ${ }^{27}$

Por el contrario, las reglas de los contratos celebrados por los consumidores son generalmente concebidas como disposiciones de tipo «protectivo»: con el fin de compensar un desequilibrio socioeconómico, ellas determinarían la preeminencia de los intereses sustanciales de los consumidores por encima de los intereses de los proveedores de bienes y servicios (los comerciantes profesionales). Se trataría, por lo tanto, de la realización de una política del derecho redistributiva en sentido lato, incompatible con el mercado y destinada — en nombre de la justicia social, precisamente- a corregir sus resultados desde el exterior.

Sin embargo, la lectura anterior no puede ser compartida. Ello resulta evidente si se supera una suerte de ilusión óptica y se evita, entonces, ponderar la nueva realidad normativa según el horizonte del ordenamiento nacional para pasar a ubicarla, de manera apropiada, en el ámbito del ordenamiento comunitario, ${ }^{28}$ caracterizado por peculiares finalidades institucionales y técnicas legislativas.

Desde el punto de vista del derecho comunitario, pues, la protección contractual del consumidor no constituye, en modo alguno, un objetivo final ni, por anotarlo así, «autosuficiente», de la intervención del legislador, sino un objetivo instrumental para la instauración y el funcionamiento del mercado único. ${ }^{29}$ Ello resulta claro, desde un inicio, si se considera que la Comunidad

27 Acerca de la identificación del contrato como "punto de incidencia y de coincidencia de la regulación jurídica de la empresa y del mercado», véase OPPO, G. «Impresa e mercato». Rivista di diritto civile, 2001, I, p. 423. También hay que subrayar, de inmediato, que la libertad contractual, a pesar de constituir un presupuesto esencial de la libertad de iniciativa económica privada y, por lo tanto, del mercado, no es, en modo alguno, un presupuesto suficiente para el funcionamiento de este último (GOODE, R. II diritto commerciale del terzo millennio. Trad. italiana de Cassandro Sulpasso. Milán, 2003, p. 49 y ss.), que, por el contrario, es constantemente puesto en peligro, justamente, por el ejercicio de la autonomía contractual (de los empresarios), por medio de, por ejemplo, la celebración de pactos de no competencia (véase, por todos, MONATERI, P. G. Op. cit., p. 411 y ss.). Así se explica, por un lado, lo indispensable de una intervención pública de regulación del mercado, a fin de proteger (y promover) la competencia (LIBERTINI, M. "Autonomia privata e concorrenza nel diritto italiano.». Rivista del diritto commerciale e del diritto generale delle obbligazioni, 2002, I, p. 433); y, por otro lado, una vez más, la necesaria intersección, para estos efectos, de normas que regulan la actividad empresarial, considerada en cuanto tal, y de normas que regulan los contratos celebrados en su ejercicio (LIBERTINI, M. Op. cit., p. 440).

28 En tal sentido, y con especial referencia a la regulación de las cláusulas abusivas, véanse las claras consideraciones de BENEDETTI, G. "Tutela del consumatore e autonomia contrattuale». Op. cit., p. 804.

29 JANNARELLI, A. "La disciplina dell'atto e dell'attività: $i$ contratti tra imprese e tra imprese e consumatori». En Trattato di diritto privato europeo. Vol. I. Op. cit., p. 64; MACARIO, F. "I diritti oltre la legge. Principi e regole nel nuovo diritto dei contratti». Op. cit., p. 489; 
Europea — contrariamente a lo que se suele creer-, incluso luego de asumidos — por el Tratado de Maastricht- compromisos propiamente dichos de política social, continúa estando privada de una competencia legislativa autónoma para encaminar la armonización de los ordenamientos jurídicos nacionales hacia la protección del consumidor. ${ }^{30}$

En efecto, si bien es cierto que el propio Tratado de Maastricht introdujo en el Tratado de institución de la Comunidad un artículo específico sobre la "protección del consumidor» —actualmente renumerado como 153 (ex 129 A) y correspondiente a un nuevo y autónomo título-, también es verdad que, según la disposición citada, los actos legislativos emanados por la Comunidad Europea para perseguir el objetivo en cuestión pueden estar constituidos, exclusivamente, por «medidas adoptadas, en virtud del artículo 95, en el marco de la realización del mercado interno» (art. 153, 3. ${ }^{\circ}$ párrafo, letra a). En cambio, las eventuales medidas de protección del consumidor que fueran independientes de la instauración y del funcionamiento del mercado interno escapan de la competencia normativa de la Comunidad (según lo dispuesto, en conjunto, por los artículos 95 y 14 del Tratado) y son admitidas, exclusivamente, en tanto y en cuanto se limiten al sostenimiento, a la integración o bien al control de la política desarrollada por los Estados miembros, tal cual se dispone, expresamente, en el artículo $153,3 .^{\circ}$ párrafo, letra $b$ ) del Tratado.

Según el modelo de política del derecho adoptado por el legislador comunitario, entonces, la protección del consumidor no es un complemento del mercado, sino algo conforme a este. Es más, si se invierte la perspectiva tradicionalmente adoptada, ella constituye un presupuesto necesario para el funcionamiento del mercado único (y, por ello, justamente, la Comunidad Europea tiene competencia en materia). ${ }^{31}$ Aquí no estamos, en efecto, ante regulaciones «finalistas», que impongan a los operadores del mercado un determinado orden de sus intereses económicos, sino de regulaciones «condicionales»: ellas crean las «reglas de juego» necesarias para que cada

además de SIRENA, P. "La nuova disciplina delle clausole abusive nei contratti stipulati con i consumatori». En U. Breccia, L. Bruscuglia y F. D. Busnelli. Il diritto privato nel prisma dell'interesse legittimo. Turín, 2001, p. 283 y ss., especialmente p. 288 y ss.; PERFUMI, C. "Modelli e sistemi nel diritto europeo dei contratti». Rivista di diritto privato, 2003, p. 829 y ss.

30 Así se expresa, aunque manifestando un juicio sustancial que tiende a ser negativo, ColuINS, H. "La giustizia contrattuale in Europa». Rivista critica del diritto privato, 2003, p. 659 y ss., especialmente 663 y ss.

31 StUYCK, J. "European Consumer Law After the Treaty of Amsterdam: Consumer Policy In or Beyond the Internal Market?». Common Market Law Review, 2000, p. 367 y ss. Véase también SEATZU, F. "Le nuove basi giuridiche della politica dei consumatori nel Trattato di Amsterdam». En II Diritto comunitario e degli scambi internazionali, 2000, p. 809 y ss. 
uno pueda perseguir sus propias ventajas individuales, según el mecanismo del mercado. 32

Por lo expuesto hasta este punto, resulta apropiado asimilar la política del derecho comunitario de los contratos con la tradición de pensamiento del liberalismo, ${ }^{33}$ ya que, aun cuando en uno de sus componentes específicos puede ser definida como "reformista» y a pesar de ser minoritaria, puede vincularse directamente con las ideas de Adam Smith que aparecen en su obra capital La Riqueza de las Naciones.

Según el reformismo liberal, el mercado es el mejor instrumento (parafraseando a Churchill, habría que decir «el peor si no existieran los demás») para incrementar el bienestar, no solamente económico sino también social, de la colectividad. En el lenguaje de los economistas, ello recibe el nombre de «eficiencia en las asignaciones». Sin embargo, el mercado, contrariamente a lo que sugieren las ideologías propiamente liberales, es una institución social bastante compleja y delicada, que no siempre está en condición de realizar

32 JaNNARELLI, A. Op. cit., passim, especialmente pp. 13, 39 y 42. Acerca de la contraposición entre regulaciones "condicionales» y regulaciones "destinadas a un fin», véase, en general, CASSESE, S. La nuova costituzione economica. 2. ${ }^{a}$ ed. Roma, Bari, 2000, p. 177. Sobre los conceptos correspondientes de nomos y thesis en el pensamiento de von Hayek, véase IRTI, N. L'ordine giuridico del mercato. 4. ${ }^{a}$ ed. Roma, Bari, 2003, p. 6 y ss.

33 JanNarelli, A. Op. cit., 115. La matriz política del derecho comunitario, en lo tocante, especialmente, a la regulación del contrato, ha sido ampliamente estudiada por SOMMA, A. Diritto comunitario vs. diritto comune europeo. Turín, 2003, passim, especialmente $p$. 21 y ss. (Del mismo autor, véase "Tutte le strade portano a Fiume. L'involuzione liberista del diritto comunitario». Rivista critica del diritto privato, 2002, p. 263 y ss.; id., "Il diritto privato liberista. A proposito di un recente contributo in tema di autonomia contrattuale». Rivista trimestrale del diritto e procedura civile, 2001, p. 263 y ss.), quien, con intenciones declaradamente polémicas, identifica en ella una "involución liberal», caracterizada por un marcado desinterés frente a los derechos sociales y a las libertades carentes de contenido económico. Más allá de cierta insistencia ideológica, y a veces moralista, de esta temática, así como de la elección, bastante discutible, del título de uno de los ensayos que se acaban de citar, el análisis de Somma es de compartir, sustancialmente, y no se aparta, en definitiva, de lo que venimos exponiendo en nuestro trabajo. Siendo así, por otro lado, parece ser que la calificación como "políticamente liberal» del derecho comunitario, contrapuesta a la de "económicamente liberal», no representa otra cosa que un expediente verbal, encaminado a manifestar, implícitamente, un juicio de valor negativo (el cual, por lo demás, aunque se agota en una opinión, si bien fundamentada, del autor en mención, corre el serio peligro de pervertirse y dar lugar a una secuela de lugares comunes en alguna medida trillados, como la reducción del ser humano a una mercadería, la lógica del provecho económico o el poder de las multinacionales). A dichas tendencia se puede sumar, culturalmente, la lectura filosóficopolítica de las codificaciones de soft law como "realización, en el sentido nuclear, de la modernidad» (son palabras de BARCELLONA, M. "La buona fede e il controllo giudiziale del contratto». En S. Mazzamuto. Il contratto e le tutele. Prospettive di diritto europeo. Turín, 2002, p. 305 y ss., quien, además, con referencia precisa al control judicial del contrato, arriba a la conclusión, radicalmente contradictoria, de que dicho control representaría el fin de la idea, típicamente moderna, de la democracia como autolegislación). 
automáticamente, por sí misma, aquel resultado óptimo. En algunos casos típicos, en efecto, y tal cual explicara, claramente, Adam Smith, sus mecanismos tienden a bloquearse y a autodestruirse. ${ }^{34}$ A fin de evitar que estas «fallas» del mercado perjudiquen el logro de la eficiencia en la asignación de recursos, el reformismo liberal auspicia adecuadas intervenciones de regulación por parte del poder público, ${ }^{35}$ solo que tales intervenciones deben ser compatibles con el mercado mismo; en otras palabras, ellas deben dictar únicamente reglas de juego apropiadas, sin sustituir a los operadores en la obtención de determinados resultados finales de producción y distribución de la riqueza. ${ }^{36}$

En la formulación original de Smith, que fue acogida, por algún tiempo, en el ordenamiento comunitario, ${ }^{37}$ el único tipo de regulación necesario estaba constituido por la protección de la competencia entre empresarios (prohibición de concentración económica y de comportamientos desleales). No había espacio, entonces, para una real protección del consumidor, porque este último era el destinatario pasivo de la política de reestructuración del mercado. Se consideraba, en otras palabras, que asegurar una efectiva y leal competencia entre los empresarios era el instrumento más eficaz para proteger al consumidor.

Sin perjuicio de lo anterior, la evolución del sistema económico capitalista ha demostrado que aquel primer tipo de regulación, a pesar de ser absolutamente necesario, no era suficiente para lograr la eficiencia en la asignación de los recursos. Esta última era perjudicada, potencialmente, por las distorsiones de la competencia entre empresarios, pero también por la imposibilidad concreta de los usuarios y consumidores finales para el ejercicio de su autonomía negocial en algunas situaciones típicas, que tendían a hacerse cada vez más frecuentes e, incluso, normales (piénsese, en particular, en los contratos en masa). El derecho de la competencia, por su naturaleza, no podía remediar este paradigma ulterior de falencia del mercado, ${ }^{38}$ determinado — como veremos seguidamente- por una estructural

LIBONATI, B. "Ordine giuridico e legge economica del mercato». En Scritti in onore di Antonio Pavone La Rosa. I, 2. Milán, 1999, p. 633 y ss., especialmente 656 y ss.

35 Para un análisis económico de ello, véase, por todos, el ensayo de G. Chirichiello. En II dibattito sull'ordine giuridico del mercato. Roma, Bari, 1999, p. 141 y ss.

36 En tal sentido, véase SCHLESINGER, P. Op. cit., p. 230. Cfr., para un examen crítico de las principales posiciones de pensamiento acerca de este tema, ALPA, G. «La c. d. giuridificazione delle logiche dell'economia di mercato». Rivista trimestrale di diritto e procedura civile, 1999, p. 725 y ss.

37 Weatherill, S. "Consumer Policy». En P. Craig y Grainne de Búrca. The Evolution of the EU Law. Oxford, 1999, p. 696 y ss.

38 MENGONI, L. "Problemi di integrazione della disciplina dei "contratti del consumatore» nel sistema del codice civile». En Studi in onore di Pietro Rescigno. III/2. Milán, 1998, p. 536. 
asimetría informativa entre las partes. ${ }^{39}$ Eran necesarias, por el contrario, nuevas reglas de derecho de los contratos, por medio de las cuales los usuarios y consumidores finales fueran puestos en verdadera condición de identificar y escoger la oferta más conveniente por parte de los empresarios. ${ }^{40}$

Las nuevas regulaciones de los contratos celebrados por los consumidores constituyen, en consecuencia, un componente indispensable para la instauración y para el funcionamiento del mercado: ${ }^{41}$ ello significa, asimismo, y

39 Véase infra, n. ${ }^{\circ}$ 3. Este tema, ampliamente examinado desde la perspectiva del análisis económico del derecho, viene suscitando una atención creciente de la doctrina (en la bibliografía italiana, véase VETTORI, G. "Le asimmetrie informative fra regole di validità e regole di responsabilità». Rivista del diritto privato, 2003, p. 241 y ss., así como la monografía de POL, M. de. Asimmetrie informative e rapporti contrattuali. Padua, 2002, trabajo que, contrariamente a lo que podría hacer creer su título, está dedicado, casi exclusivamente, a la responsabilidad precontractual; en la bibliografía alemana, destaca el amplio estudio de FLEISCHER, H. Informationsasymmetrie im Vertragsrecht. Colonia, 2001).

40 Jannarelli, A. Op. cit., p. 24 y ss. En ausencia de dichas reglas, los usuarios y los consumidores finales orientan sus decisiones en función del precio (SCITOVSKI, T. «Some Consequences of the Habit of Judging Quality by Price». Revue of Economic Studies, vol. 12, 1945, p. 100 y ss.), con la consecuencia, paradójica, de que se producen resultados no óptimos en el mercado (STIGLITZ, J. "The Causes and the Consequences of the Dependance of Quality on Price». Journal of Economic Literature, vol. 25, 1987, p. 1 y ss.). Así se manifiesta, como alguien ha remarcado (LIPARI, N. "Diritto e mercato della concorrenza». En N. Musu. La concorrenza tra economia e diritto. Milán, Roma, Bari, 2000, p. 34 y ss.), una peculiar intersección entre la perspectiva económica y la perspectiva jurídica de las relaciones de competencia, porque el funcionamiento del mercado depende, cada vez con mayor incidencia, de la disponibilidad de informaciones legales, relativas al contenido preceptivo del contrato con el cual se realizan las distintas transacciones. Recíprocamente, ninguna intervención legislativa para la reconstrucción del mercado puede incidir, de manera efectiva, en las las dinámicas de este, a menos que aborde los aspectos de la información (LIPARI, N. "Il mercato: attività privata e regole giuridiche». En S. Gambino, N. Irti et. al. Il diritto della transizione. Milán, 1998, p. 50).

41 Resulta significativo que referencias coincidentes, en tal sentido, se presenten no solamente en algunos trabajos ensayísticos "de punta» (ALESSI, R. "LuCi ed ombre del nascente diritto europeo dei contratti». En su edición Diritto Europeo e autonomia contrattuale. Palermo, 1999, p. 7 y ss., especialmente 22 y ss., y 44 y ss.; FERRI, G. B. "La "cultura» del contratto e le strutture del mercato». En N. Lipari. Diritto privato europeo e categorie civilistiche. Nápoles, 1998, p. 170; BARCELLONA, P. "Soggetti e tutele nell'epoca del mercato europeo/mondiale». En la misma obra, p. 71; GABRIELLI, E. "Sulla nozione di consumatore». Rivista trimestrale di diritto e procedura civile, 2003, p. 1149 y ss., especialmente 1170 y ss.; IRTI, N. Op. cit., p. 83; IUDICA, G. "Clausole abusive e razionalità del mercato». En C. M. Bianca, F. D. Busnelli et al. (eds.). Commentario al capo XIV bis del codice civile: dei contratti del consumatore. A su vez en Le Nuove leggi civili commentate. 1997, p. 777 y ss.; JANNARELLI, A. Op. cit., passim, especialmente, p. 57, 61), sino también en una obra de carácter tratadístico como la de ROPPO, V. «ll contratto». En G. Iudica y P. Zatti. Trattato di diritto privato. Milán, 2001, p. 903 y ss., que, por su naturaleza (como lo destaca el mismo autor en su volumen Il contratto del duemila. Op. cit., p. VII), está destinada a reflejar el "cuadro institucional» de la materia, con la identificación de "un apreciable grado de estabilidad y definición». 
para nuestros fines, que se debe negar toda pretendida incompatibilidad de tales regímenes con el derecho general del contrato. ${ }^{42}$

\section{Sigue: El valor de la autonomía negocial}

Hasta este punto, hemos tomado en consideración el contrato "por sí mismo», es decir, en tanto y en cuanto instrumento. Ahora conviene examinar de qué forma las regulaciones que venimos analizando asumen al contrato "en sí mismo", es decir, como acto de autonomía privada. Así verificaremos si tales regulaciones se apartan de modo significativo del derecho común.

La perspectiva indicada resulta significativa, en efecto, porque la bibliografía especializada tiende a concebir la protección de los consumidores como un valor que se contrapone, sistemáticamente y axiológicamente, al valor de la autonomía negocial: la limitación de esta última, por parte del poder público — que ha interesado, de manera progresiva y en medida más o menos incisiva, a todos los ordenamientos jurídicos europeos de la posguerra-, habría sido extendida hasta sus extremas consecuencias por parte del legislador comunitario, a tal punto que se pone en duda incluso su ligar central en el derecho de los contratos. Retomando el título de un afortunado ensayo de Medicus, se podría sostener que el derecho de los contratos celebrados por los consumidores es percibido como una suerte de «adiós a la autonomía privada». ${ }^{43}$

A favor de la tesis que acabamos de exponer puede haber influido el hecho de que el derecho nacional está constituido, en medida claramente preponderante, por normas que admiten excepciones, ${ }^{44}$ las cuales, por definición,

42 BENEDETTI, G. "Tutela del consumatore e autonomia contrattuale». Op. cit., p. 804.

43 MEDICUS, D. Abschied von der Privatautonomie im Schuldrecht? Colonia, 1994. Al respecto, se puede consultar la reseña de BARENGHI, A. "Il dibattito tedesco sulla fideiussione bancaria: a proposito di un recente saggio». Banca, borsa e titoli di credito, 1995, I, p. 101 y ss.; y, del mismo autor, "Una pura formalità. A proposito di limiti e di garanzie dell'autonomia privata in diritto tedesco». La Nuova giurisprudenza civile commentata. 1995, I, p. 197 y ss., en la que se comenta la ya célebre sentencia del Tribunal Constitucional alemán (Bundesverfassungsgericht) del 19 de octubre de 1993.

44 Véase, por todos, RUSSO, E. "Norma imperativa, norma cogente, norma inderogabile, norma indisponibile, norma dispositiva, norma suppletiva». Rivista di diritto civile, 2001, I, p. 580, 596, quien considera que «el carácter dispositivo de las normas civiles es un carácter generalísimo, dado que la ley civil actúa frente a un poder (la autonomía privada) que es la facultad de imponer normas jurídicas». De ello se deduciría que "las normas de ius cogens e imperativas constituyen islas en el mar del derecho [privado]». Sobre este punto, se ha detenido, hace poco, GAMBARO, A. "Contratto e regole dispositive». Rivista di diritto civile, 2004, I, p. 4. Por lo demás, se aprecia comúnmente que, como ya hemos señalado en estas páginas, la preeminencia original de las normas que 
no pueden concebirse como una limitación de la autonomía negocial de las partes; en cambio, el derecho comunitario comprende exclusivamente normas que no admiten excepciones. Del cotejo, en mayor o menor medida consciente, entre estas dos realidades normativas, se puede derivar la impresión, precisamente, de que el derecho comunitario suprime aquel espacio de libre ejercicio de la autonomía negocial que, en el ámbito de cada ordenamiento jurídico nacional, es garantizado, por el contrario, por las numerosas normas dispositivas o supletivas.

Empero, el razonamiento anterior resulta metodológicamente insostenible, porque presupone una suerte de incebible comparación entre el derecho nacional y el derecho comunitario, que, por el contrario, en tanto se basan en presupuestos sistemáticos e institucionales distintos, son prácticamente inconmensurables.

En general, el derecho comunitario no es, en modo alguno, una expresión de aquella soberanía que, si bien con modalidades y límites históricamente condicionados, ha caracterizado a los Estados nacionales modernos. Ello se debe, sobre todo, a que se trata de un derecho íntimamente vinculado con el principio fundamental de la subsidiariedad, actualmente previsto en el artículo 5, 2. ${ }^{\circ}$ párrafo, del Tratado institutivo de la Comunidad Europea. Sobre la base de este principio, su competencia para emanar disposiciones de armonización de los ordenamientos jurídicos nacionales subsiste solo en tanto y en cuanto sea estrictamente necesario para el logro de sus objetivos institucionales. Así pues, y en particular, el régimen del contrato dictado por el derecho comunitario puede estar constituido exclusivamente por reglas que son indispensables (y no ya puramente «útiles») para la instauración y para el funcionamiento del mercado único, porque es en ello - como ya anotamos- ${ }^{45}$ donde hay que identificar el correspondiente objetivo institucional de la Comunidad Europea.

Ahora bien, las reglas que corresponden a las normas dispositivas previstas, con carácter general, por el derecho nacional, no pueden considerarse, por definición, como indispensables para el funcionamiento del mercado, justamente porque admiten excepciones, y dependen, por lo tanto, de la

admiten excepciones en materia contractual ha sido progresivamente alterada por la legislación más reciente, que, por un lado, ha introducido en el régimen del contrato un número creciente de normas que no admiten excepciones (véase, por todos, ROPPO, V. II contratto del duemila. Op. cit., p. 12 y ss.) y, por otro lado, no ha cumplido con formalizar en normas que admiten excepciones los nuevos tipos negociales de la realidad socioeconómica (NOVA, G. de. "I singoli contratti: dal titolo III del libro IV del codice civile alla disciplina attuale». Op. cit., p. 495 y ss.; Id. "Contratto: per una voce». Op. cit., p. 651; cfr., igualmente, GAMBARO, A. Op. cit., p. 16).

45 Véase retro, $n^{\circ} 2$ 
voluntad de las partes. Dichas reglas tienen una función más modesta, pero de todas maneras útil: facilitar el ejercicio de la autonomía negocial, a través, principalmente, de una reducción de los costos de transacción. ${ }^{46}$ Aunque ellas no existieran, entonces, el mercado estaría en perfectas condiciones de funcionamiento, y esta, ni más ni menos, es la razón por la cual, sobre la base del citado principio de subsidiariedad, no han sido armonizadas por el legislador comunitario (ni tampoco sometidas, coherentemente, al juicio de compatibilidad con el Tratado institutivo de la Comunidad Europea por parte del Tribunal de Justicia de las Comunidades Europeas).

Lo anterior explica también la razón por la cual el derecho comunitario de los contratos está constituido, exclusivamente, por normas que no admiten excepción: ello no se debe a que tal derecho suprima el papel de la autonomía privada en la constitución del precepto contractual, sino a que es un derecho constitutivamente vinculado, sobre la base del principio de subsidiariedad, al cometido de no armonizar los ordenamientos jurídicos nacionales en lo tocante a sus normas que admiten excepciones, las cuales representan, en la actualidad, la mayor parte del régimen contractual. Y esta limitación, a su vez, no solo es compatible con el valor de la autonomía negocial de las partes, sino que está dirigida, es más, a permitir su máxima expansión posible en el derecho europeo: no armonizar las normas dispositivas de los ordenamientos jurídicos nacionales significa, efectivamente, dejar a la libertad de elección de las partes, garantizada por el artículo 3 del Convenio de Roma sobre la ley aplicable al contrato, una multiplicidad de órdenes diversificados de reglas, en potencial competencia entre ellos. ${ }^{47}$

En segundo lugar, hay que destacar que las normas del derecho comunitario de los contratos, a pesar de no admitir excepciones, casi nunca imponen a las partes un determinado orden de intereses; lo que hacen es dejar a las partes en libertad de determinar el contenido de su acuerdo. ${ }^{48}$ En su mayor parte, dichas normas dictan reglas que obligan al comerciante profesional a

46 AnGelicl, C. Op. cit., p. 5; Gambaro, A. Op. cit., p. 5, p. 10; Jannarell, A. Op. cit., p. 21, 30 y ss. En la bibliografía que profesa el análisis económico del derecho, véase, especialmente, PARDOLESI, R. "Regole di default e razionalità limitata: per un (diverso) approccio di analisi economica al diritto dei contratti». Rivista critica del diritto privato, 1996, p. 451 y ss.; y, más recientemente, BELLANTUONO, G. "Le regole di default nel diritto dei contratti». Rivista di diritto civile, 2000, I, p. 427 y ss.; id., "Contratti incompleti e norme sociali». Rivista critica del diritto privato, 2001, p. 261 y ss.

47 Cfr., al respecto, CAFAGGI, F. "Una governance per il diritto europeo dei contratti». En Quale armonizzazione per il diritto europeo dei contratti? Op. cit., p. 183 y ss., así como, más en general, los ensayos compilados en ZopPINI, A. (ed.). La concorrenza tra ordinamenti giuridici. Roma, Bari, 2004.

48 Se trata, por lo tanto, de normas de ius cogens, pero no imperativas, o, si se prefiere una remota terminología, "prohibitivas» (sobre esta distinción véase, de lo reciente, RUSSO, E. Op. cit., p. 580 y ss.). 
brindar determinadas informaciones al consumidor ${ }^{49}$ pero sin prohibir o imponer ninguna cláusula contractual.

Lo que indicamos no es simplemente el fruto de una determinada y contingente decisión de política del derecho. Estamos, ante todo, frente a una consecuencia necesaria del principio de proporcionalidad, previsto en el artículo 5, 3. ${ }^{\circ}$ párrafo, del Tratado institutivo de la Comunidad Europea. Entre diversas soluciones idóneas para realizar un determinado objetivo institucional, la Comunidad Europea está obligada a elegir la que determine el menor sacrificio posible de las libertades fundamentales. ${ }^{50}$

En particular - y como ya anotamos-, las reglas de los contratos celebrados por los consumidores han sido dictadas con el fin esencial de eliminar aquellas asimetrías informativas entre las partes, asimetrías que determinan la falla del mercado. ${ }^{51} \mathrm{Y}$ el instrumento menos coercitivo para eliminar una asimetría informativa está constituido, justamente, por reglas que garanticen a la parte menos informada (el consumidor) la obtención de la información necesaria para una adecuada y consciente valoración de la conveniencia de la operación que realizará. Por lo general, esto acontece imponiendo a la parte más informada (el comerciante profesional) la obligación de proporcionar dicha información (la llamada «disclosure»). ${ }^{2}$ Solo cuando dichas reglas resultan, por excepción, insuficientes para eliminar determinadas asimetrías

49 Véase, por todos, ALESSI, R. Op. cit., p. 20 y ss. Los conceptos tradicionales de forma y de objeto del contrato deben ser, por consiguiente, reexaminados (véase VALENTINO, D. Obblighi di informazione, contenuto e forma negoziale. Nápoles, 1999, especialmente p. 133 y ss.), y lo mismo cabe decir del problema clásico de la formación del acuerdo (véase NAZZARO, A. C. Obblighi d'informare e procedimenti contrattuali. Nápoles, 2000, p. 168 y ss.).

${ }^{50}$ Una consideración análoga es válida, desde luego, para el derecho italiano, porque este último se encuentra comprometido por la decisión sistemática a favor del mercado y de la competencia (IRTI, N. Op. cit., p. 140).

51 Dicho planteamiento es claramente compartido por BENEDETTI, G. II diritto comune dei contratti e degli atti unilaterali. Op. cit., p. 155, y por IRTI, N. Op. cit., p. 140, aunque ambos formulan apreciaciones bastante diferentes acerca del significado de la autonomía contractual en la realidad socioeconómica del capitalismo avanzado, sobre todo en lo concerniente a los contratos en masa. Con carácter más general, se ha destacado, de manera convincente, que «el problema central, [...] en nuestra sociedad, no parece ser el de garantizar la equidad del contenido económico del contrato, sino el de atacar aquellas perturbaciones o prejuicios de la libertad de decisión (especialmente por asimetrías informativas) que sean capaces de incidir en una adecuada valoración de la Conveniencia de la operación» (SCHLESINGER, P. Op. cit., p. 231; las cursivas son añadidas). En cambio, en el sentido de que las reglas de información son suficientes para proteger los intereses de los cuales son portadores los sujetos débiles y deben, por ello, ir acompañadas de la condificación de sus derechos sustanciales, véase ALPA, G. "La C. d. giuridificazione delle logiche dell'economia di mercato». Op. cit., p. 756 y ss.

52 Al respecto, sigue siendo fundamental el estudio de COFFEE, J. C. "Market Failure and the Economic Case for a Mandatory Disclosure System». Virginia Law Review, vol. 70, 1984, p. 717 yss. 
informativas, el derecho comunitario de los contratos impone un determinado orden final de los intereses contractuales o bien somete la autonomía negocial — como ocurre en el régimen de las cláusulas abusivas - a un control sustancial por parte de la autoridad judicial. ${ }^{53}$

Se ha escrito que las libertades fundamentales garantizadas por el Tratado están dirigidas a permitir el ejercicio de la autonomía contractual más allá de las fronteras nacionales, ${ }^{54}$ y la jurisprudencia del Tribunal de Justicia de las Comunidades Europeas en materia de «medidas de efecto equivalente», prohibidas por los artículos 28 y 29 del Tratado, confirma ampliamente dicha lectura. Pero ella vale también, a pesar de todas las apariencias, para el derecho comunitario secundario, que ha armonizado los ordenamientos jurídicos nacionales. En efecto, si bien es cierto que tal derecho no se limita a cumplir una función de liberalización del mercado, sino que cumple también una función ulterior, de reregulación (condicional) del mercado, ${ }^{55}$ no es menos verdadero que esta última está dirigida, precisamente, a hacer que las transacciones económicas se desarrollen de conformidad con el mecanismo de la autonomía privada.

La protección del consumidor en el derecho comunitario de los contratos se realiza, en especial, por medio de las reglas necesarias para restituir a aquel su autodeterminación o soberanía económica, ${ }^{56}$ que se funda en la libertad de elegir, entre las propuestas alternativas formuladas por los empresarios, aquella que resulte más ventajosa. ${ }^{57}$ En ello — como se ha

53 GABRIELLI, E. Op. cit., p. 1178 y ss.

54 Müller-GrafF, P. C. "Europäisches Gemeinschaftsrecht und Privatrecht - das Privatrecht in der europäischen Integration». Neue Juristische Wochenschrift. 1993, p. 14.

55 Véase retro, $n .^{\circ} 2$.

56 También las tendencias doctrinales favorables a orientar el derecho europeo de los contratos en un sentido altamente solidarista han aceptado, por lo general, dicho modelo, si bien sosteniendo la necesidad de que se refuerce la protección de la parte más débil desde el punto de vista social, además de económico (véase, principalmente, WILHELMSSON, T. Social Contract Law and European Integration. Dartmouth, 1995, p. 35 y ss.). Para una crítica radical, en cambio, cfr. SOMMA, A. "ll diritto privato liberista. A proposito di un recente contributo in tema di autonomia contrattuale». Op. cit., p. 263 y ss., y, ya en su ensayo anterior, "ll diritto dei consumatori è un diritto dell'impresa». Politica del diritto, 1998, p. 679 y ss., en el que el autor citado percibe los indicios de una "aproximación hedonista al tema del consumo», así como la aplicación de una política del derecho preconcebida para «relegar» a la Constitución el valor de la solidaridad o del comercio equitativo y solidario. La alternativa estaría representada, entonces, por una recuperación amplia del principio de la justicia conmutativa y por la despotenciación de la autonomía privada en el desarrollo de los derechos de tercera generación (que, superando la concepción pandectística de sujeto jurídico, protegen al ser humano en tanto enfermo, anciano, etc.).

57 IRTI, N. Op. cit., p. 102 y ss.; JANNARELLI, A. Op. cit., p. 43 y 47. En la bibliografía alemana, véase la detallada monografía de DREXL, J. Die wirtschaftliche Selbstbestimmung des Verbrauchers. Tubinga, 1998. 
resaltado- ${ }^{58}$ radica el principio fundamental de la autonomía privada, modernamente entendido.

Es indudable que dicha intervención de regulación del mercado limita a la autonomía negocial del empresario oferente, ${ }^{59}$ pero no se puede sostener que la correspondiente compresión de contenido de dicho poder jurídico sea incompatible con la tradición liberal de los ordenamientos jurídicos nacionales: en general, en efecto, el legislador comunitario no prescribe ni prohíbe al empresario perseguir un determinado interés económico, sino que se limita, con algunas excepciones, a reglamentar las modalidades con las cuales este último puede ser satisfecho por medio del contrato. ${ }^{60} \mathrm{Ni}$

58 BARCELlona, P. Op. cit., p. 71.

59 MENGONI, L. Op. cit., p. 536.

60 Se puede negar, entonces, que el fundamento jurídico de dichas regulaciones esté constituido por la equidad (del contrato), propiamente asociada con la justicia conmutativa del intercambio (para un examen crítico de dicha noción, véase, en general, FRANZONI, M. "Buona fede ed equità tra le fonti di integrazione del contratto». En Contratto e impresa. 1999, p. 83 y ss.; y RUSSO, D. Sull'equità dei contratti. Nápoles, 2001, p. 15 y ss.). Contrariamente, se ha sostenido que la nulidad de las cláusulas abusivas es la consecuencia de una valoración de su naturaleza inequitativa concreta (GAZzONI, F. Manuale di diritto privato. 10. ${ }^{a}$ ed. Nápoles, 2003, p. 774), quel presupondría el poder del juez para establecer, según un criterio de razonabilidad, el equilibrio de los intereses concurrentes (MENGONI, L. Op. cit., passim, especialmente p. 546 y ss.). Sin embargo, dichos planteamientos doctrinales no parecen ser de compartir (véase, en tal sentido, Castronovo, C. "Profili della disciplina nuova delle clausole c. d. vessatorie cioè abusive». Europa e diritto privato, 1998, I, p. 30 y ss.). El juicio sobre la naturaleza abusiva, previsto por los artículos 1469-bis y ss. del Código Civil, se explica y justifica siempre y cuando las cláusulas contractuales (unilateralmente predispuestas por el comerciante profesional) integren o modifiquen in peius, frente al consumidor, una norma jurídica, destinada a sustituirlas cada vez que sean declaradas ineficaces (SIRENA, P. Commentario sub art. 1469-ter, 3. ${ }^{\text {er }}$ párrafo. En G. Alpa y S. Patti (eds.). Clausole vessatorie nei contratti con i consumatori. A su vez en II Codice Civile. Commentario, fundado por Schlesinger y ahora dirigido por F. D. Busnelli. Milán, 2003, p. 890 y ss.): el equilibrio contractual del que se apartan las cláusulas abusivas, por lo tanto, está constituido, propiamente, por el modelo legal de los derechos y de los deberes contractuales (cfr., sin embargo, Trolano, S. Commentario sub art. 1469-bis, $1^{\text {er }}$. Párrafo. En op. ult. cit., p. 71 y ss.), en el cual, para lo que nos interesa, se puede identificar, si así se prefiere, la equidad del contrato (en tal sentido, es válida la máxima: "Aequitas legislatori, jus iudici magis convenit», formulada, con la inversión paradójica de un antiguo aforismo, por SCIALOJA, V. "Del diritto positivo e dell'equità (Discorso inaugurale letto nella grande Aula della Biblioteca Valentiniana il giorno 23 novembre 1879 nel solenne riaprimento degli studi nell'Università di Camerino)». Camerino, 1880, p. 16 [non vidi]). La determinación de que la cláusula (unilateralmente predispuesta por el comerciante profesional) se aparta de la norma jurídica en sentido favorable al consumidor no es suficiente, por otro lado, para que ella sea declarada abusiva, porque, tal cual lo establece el propio artículo 1469-bis, 1 er $^{\text {er }}$ parrafo del Código Civil, es necesario que dicho equilibrio sea considerado por el juez como «significativo». Empero, esta última consideración no conlleva, como es evidente, el ejercicio de ningún poder equitativo, sino solamente aquella natural discrecionalidad que compete al juez en el juicio de hecho, en particular cuando entran a tallar conceptos elásticos como el aquí 
siquiera la propia regulación dictada en los artículos 1469-bis y ss. del Código Civil - a pesar de comportar, en definitiva, un vínculo de contenido de la libertad contractual del comerciante profesional- ${ }^{61}$ prohíbe al empresario, sin más, la predisposición de cláusulas abusivas. ${ }^{62}$ Todo lo que se hace es prescribir que tales cláusulas sean individualmente negociadas con el consumidor o bien reequilibradas con otras cláusulas del contrato. ${ }^{63}$

En último análisis, el límite que las reglas aquí tratadas imponen a la libertad contractual del empresario está representado, propiamente, por la prohibición del abuso de la autonomía negocial, ${ }^{64}$ prohibición que, además

mencionado. Radicalmente distinta es, en cambio, la perspectiva teórica que nos dice que, en la regulación analizada, el precepto de la buena fe se especificaría como un principio de equidad contractual que el predisponente debería respetar en el ejercicio de su poder (de hecho) (así se expresa BIANCA, C. M. "Le tecniche di controllo delle clausole vessatorie», publicado originalmente en C. M. Bianca y G. Alpa. Le clausole abusive nei contratti stipulati con i consumatori. Padua, 1996; y ahora en id. Realtà sociale ed effettività della norma. Scritti giuridici. II/2. Milán, 2002, p. 634, y en id. Diritto civile. III. Op. cit., p. 379 y ss. [nota 26]). A esta última afirmación, que en el fondo es de compartir, se puede replicar, de todas maneras, solo que la referencia a la equidad, en tanto parece invocar las posiciones doctrinales antes examinadas, corre el riesgo de ser desorientador y de suscitar, de cualquier forma, reacciones críticas inútiles. Una preocupación análoga parece poderse advertir en la tesis que asigna al principio general de la buena fe, según los artículos 1469-bis y ss. del Código Civil, el papel de guiar y de delimitar el juicio sobre la equidad de las cláusulas contractuales (BUSNELLI, F. D. "Note in tema di buona fede ed equità». Rivista di diritto civile, 2001, I, p. 544 y ss.; y, desde una perspectiva equivalente, MACARIO, F. "I diritti oltre la legge. Principi e regole nel nuovo diritto dei contratti». Op. cit., p. 514 y ss.). Nos podemos preguntar, sin embargo, y una vez más, si la referencia a la equidad, a pesar de estar nítidamente subordinada al papel decisivo de la buena fe, resulta indispensable, efectivamente, a fin de explicar dogmáticamente la regulación que venimos analizando.

61 ROPPO, V. Il contratto del duemila. Op. cit., p. 31.

62 JanNarelli, A. Op. cit., p. 95 y ss.

63 En lo que atañe a las cláusulas enumeradas en el artículo 1469-quinquies, 2. ${ }^{\circ}$ párrafo del Código Civil, está expresamente previsto por el legislador que la prueba de la eventual tratativa individual no descarta la naturaleza abusiva. Sin embargo, y contrariamente a una difundida opinión, hay que admitir, en virtud del artículo 1469-quinquies, $1{ }^{\circ}$ párrafo del Código Civil, que el comerciante profesional puede, de todas maneras, evitar que tales cláusulas sean declaradas ineficaces, siempre que demuestre que ellas son equilibradas por otras cláusulas del contrato o que están justificadas por las circunstancias existentes al momento de la celebración (para las referencias bibliográficas respectivas, véase SiRENA, P. Commentario sub art. 1469-bis, 3. ${ }^{\text {er }}$ párrafo, del Código Civil. En Clausole vessatorie nei contratti con i consumatori. Op. cit., p. 215).

64 La legitimidad de dicho límite a la autonomía negocial del empresario se funda, claramente, en el artículo 41, 2. ${ }^{\circ}$ párrafo, de la Constitución (LIPARI, N. "Il mercato: attività privata e regole giuridiche». Op. cit., p. 53; OPPO, G. "Note sulla contrattazione d'impresa». Rivista di diritto civile, 1995, I, p. 639; seguidos por SIRENA, P. "La nuova disciplina delle clausole abusive nei contratti stipulati con i consumatori». Op. cit., p. 289). Como es sabido, es arduamente controvertida la cuestión de si la Constitución protege el mercado (para las tesis positivas, véase LIBERTINI, M. Op. cit., p. 441; LIBONATI, B. Op. cit., p. 644 y ss.; MENGONI, L. "Persona e iniziativa economica privata nella 
de no ser incompatible con la autonomía negocial, sirve para preservar la función sustancial de esta última. ${ }^{65}$ Así se consigue que el conflicto de intereses entre las partes se componga según los mecanismos del mercado con una maximización del bienestar colectivo. ${ }^{66}$ Para tal fin es necesario, precisamente, que se prohíba al empresario aprovecharse de la falencia del mercado, porque dicho comportamiento, en lugar de incrementar la riqueza de la colectividad, la destruiría. ${ }^{67}$

Según esta descripción, la prohibición del abuso de la autonomía negocial, que sirve de base de las reglas aquí tratadas, puede asociarse con el

Costituzione». En G. Vettori (ed.). Persona e mercato. Padua, 1996, p. 35 y ss.; id. "Problemi di integrazione della disciplina dei "Contratti del consumatore» nel sistema del codice civile». Op. cit., p. 535 y ss.; PERLINGIERI, P. "Mercato, solidarietà e diritti umani». Rassegna di diritto civile, 1995, p. 101 y ss.). Al parecer, sin embargo, la disposición citada no es idónea para salvaguardarlo, porque ella establece que la iniciativa económica privada no puede desenvolverse en oposición a la "utilidad social» (véase Oppo, G. "L'iniziativa economica». Rivista di diritto civile, 1988, I, p. 332). Partiendo de la ya clásica concepción de dicha cláusula como "fórmula verbal que resume una serie de intereses con relevancia social, que el legislador ha hecho propios» (Nuzzo, M. Utilità sociale e autonomia privata. Milán, 1974, p. 81), se debe considerar, justamente, que ella, en la realidad actual del ordenamiento jurídico, no puede dejar de tomar en consideración el funcionamiento del mercado, que ha sido elevado, como quiera que sea, a principio preeminente y conformativo de la economía, en virtud del Tratado institutivo de la Comunidad Europea (sobre este último, véase IRTI, N. Op. cit., passim, en especial p. 20 y ss., 125 y ss., y 137 y ss., quien denuncia, sin embargo, la "antinomia entre Constitución económica y opción de sistema»; cfr., igualmente, LIBONATI, B. Op. cit., p. 657 y ss.). Por otro lado, la relevancia constitucional del mercado y de la libre competencia empresarial, en términos de "utilidad social», permite que estos sean, imperiosamente, equilibrados con los demás intereses jurídicos que también son relevantes y, como expresamente se prevé en el artículo 41, 2. ${ }^{\circ}$ párrafo, de la Constitución, y que cumplan con la exigencia de evitar daños "a la seguridad, a la libertad, a la dignidad humana» (OPPO, G. "Le ragioni del diritto: il diritto commerciale». Rivista di diritto civile, 1995, I, p. 505 y ss.; id., "Impresa e mercato». Op. cit., p. 423 y ss.). Resulta bastante significativo, por lo demás, que la propia teoría económica, a pesar de proclamar a grandes voces la absoluta autosuficiencia de su objeto, en comparación con lo que ocurre con el derecho, identifique en la utilidad social, justamente, el fin último de la competencia, con lo cual establece, de manera implícita, el confín de la recíproca interrelación del mercado con el ordenamiento jurídico (LIPARI, N. "Diritto e mercato della concorrenza». Op. cit., p. 33). Queda sentado, en todo caso, que las prestaciones del Estado social no pueden estar sujetas a un mal entendido "primado del mercado», aunque el principio de eficiencia tenga que determinar, como quiera que sea, sus condiciones de factibilidad económica (MENGONI, L. "Persona e iniziativa economica privata nella Costituzione». Op. cit., p. 39 y ss.). AulETTA, T. Op. cit., p. 228 y ss.

66 Véase retro, $n .^{\circ} 2$.

67 SACCO, R. "L'abuso della libertà contrattuale». En Diritto privato, 1997. T. III: "L'abuso del diritto». Padua, 1998, p. 232 y ss., quien identifica en ello, con carácter general, la esencia del abuso de la libertad negocial (aunque luego, en la p. 234, manifiesta dudas sobre la utilidad teórica de tal noción en tanto distinta de la noción de los vicios de la voluntad y de la buena fe). 
contenido preceptivo que los ordenamientos jurídicos de Europa continental han asignado, por lo general, al principio de la buena fe contractual, ${ }^{68}$ aun cuando este se manifieste, a veces (y sobre todo en relación con el control del carácter abusivo de las cláusulas unilateralmente predispuestas) con una insistencia hasta el momento desconodida en el derecho italiano (pero ampliamente experimentada, como se sabe, en el derecho alemán). ${ }^{69}$ Y se ha resaltado que ello constituye, ciertamente, una evolución pero no una revolución del sistema. ${ }^{70}$

68 Barcellona, P. Op. cit., p. 69; Castronovo, C. Op. cit., p. 34 (cfr., sin embargo, en sentido contrario, MENGONI, L. "Problemi di integrazione della disciplina dei "Contratti del consumatore» nel sistema del codice civile». Op. cit., p. 540 y ss.; D'AMICO, G. "Regole di validità e di comportamento nella formazione del contratto». Rivista di diritto civile, 2002, I, p. 50, 59; y en la obra anterior del mismo autor "Regole di validità» e principio di correttezza nella formazione del contratto. Nápoles, 1996, p. 336 y ss.). En general, hay que entender que la noción de la buena fe contractual puede determinarse, justamente, "partiendo del derecho de los tráficos y de los usos del tráfico comercial» (RESCIGNO, P. "Rimeditazioni sulla buona fede: omaggio ad Alberto Burdese». En L. Garofalo (ed.). Il ruolo della buona fede oggettiva. Atti del Convegno internazionale di studi in onore di Alberto Burdese. Tomo IV. Padua, 2003, p. 573) e identificando su esencia en las reglas de fair dealing que sirven para sancionar las jugadas prohibidas en el juego antagonístico del mercado (en tal sentido, véase MONATERI, P. G. Op. cit., p. 413; y BARCELLONA, P. Op. cit., p. 324 y ss.). La consolidada connotación solidarista de la buena fe, por más de compartir que sea, corre el riesgo de ser desorientadora, porque tiene como característica la (consciente) implicación de valores no patrimoniales, extraños o incluso incompatibles con la llamada "lógica del mercado». Por ello, se alimentan, asimismo, las hostilidades, o por lo menos las desconfianzas, de los juristas anglosajones respecto de la propia noción de «buena fe» (véanse, al respecto, los ensayos compilados en el volumen ZIMMERMANN, R. y S. WHITTAKER (eds.). Good Faith in European Contract Law. Cambridge, 2000; e, igualmente, GOODE, R. "The Concept of "Good Faith» in English Law». En Saggi, conferenze e seminari, n. ${ }^{\circ} 2$, Roma, Centro di studi e ricerche di diritto comparato e straniero, 1992. En la bibliografía italiana, véase VITA, A. de. "Buona fede e common law. Attrazione non fatale nella storia del contratto». En II ruolo della buona fede oggettiva. Atti del Convegno internazionale di studi in onore di Alberto Burdese. I. Op. cit., p. 459 y ss.; y también, con especial referencia a la regulación de las cláusulas abusivas, véase ANTONIOLLI DEFLORIAN, L. "L'interazione del diritto inglese con il diritto comunitario: I'esempio della direttiva sulle clausole abusive nei contratti con i consumatori ed il principio di buona fede». Rivista di diritto civile, 2002, I, p. 451 y ss.).

69 PATTI, S. "Significato del principio di buona fede e clausole vessatorie: uno sguardo all'Europa». En II ruolo della buona fede oggettiva. Atti del Convegno internazionale di studi in onore di Alberto Burdese. III. Op. cit., p. 59 y ss. La armonización de los ordenamientos jurídicos nacionales europeos ha hecho, por lo tanto, que la buena fe pueda ser considerada, sin más, como un principio general del derecho europeo de los contratos (BIANCA, C. M. "Buona fede e diritto privato europeo». En Il ruolo della buona fede oggettiva. Atti del Convegno internazionale di studi in onore di Alberto Burdese. III. Op. cit., p. 202 y ss.; cfr., sin embargo, Collins. "Good Faith in European Contract Law». Oxford Journal of Legal Studies, vol. 14, 1999, p. 229 y SS.; VETTORI, G. "Buona fede e diritto europeo dei contratti». Europa e diritto privato, 2002, p. 915 y ss.).

70 BUSNELLI, F. D. Op. cit., p. 543, quien opina que actualmente se puede afirmar que "la función del corregir ha devenido [...] el proprium del papel de la buena fe». La regula- 


\section{El análisis estructural: el presupuesto objetivo de aplicación}

La inexistencia de una efectiva incompatibilidad axiológica entre los contextos normativos tomados en consideración —admitiendo que los argumentos anteriormente expuestos sean de compartir- es una condición necesaria, pero no suficiente, para adscribir las reglas de los contratos celebrados por los consumidores a la parte general del contrato.

Para estos efectos, es necesario verificar ulteriormente, y desde el punto de vista estructural, si las mencionadas reglas prevén una fattispecie de contrato que pueda definirse, justamente, como "general». Al parecer, ello está descartado de plano, dada la específica delimitación de su ámbito subjetivo de aplicación, que constituye su característica peculiar y, es más, según el planteamiento conceptual más difundido, su propia razón sustancial. Aquí, en efecto, estamos ante normas que, al margen de la identificación de sus presupuestos objetivos, son aplicables solamente si el contrato ha sido celebrado por un comerciante profesional y, generalmente, por un consumidor. ${ }^{71}$

Se ha sostenido que la relevancia de dichas cualidades subjetivas de las partes contratantes constituye la base normativa para la creación de una autónoma categoría de los "contratos de los consumidores», potencialmente distinta y contrapuesta a la categoría de los "contratos comerciales». Con ello, entraría en crisis la unitariedad, no solo del régimen general del contrato, previsto en el Código Civil, sino también del derecho privado mismo:

ción de los artículos 1469-bis y ss. del Código Civil, en efecto, está claramente fundada en la idoneidad del principio general de buena fe para determinar la nulidad de la cláusula contractual que lo lesione (BIANCA, C. M. Diritto civile. T. III. Op. cit., p. 389). Por lo tanto, contrariamente a cierta posición doctrinal (MENGONI, L. "Problemi di integrazione della disciplina dei "contratti del consumatore" nel sistema del codice civile». Op. cit., p. 543 y ss.; D'AMICO, G.. «Regole di validità e di comportamento nella formazione del contratto». Op. cit., p. 40 y ss.; e id., "Regole di validità» e principio di correttezza nella formazione del contratto. Op. cit., p. 9 y ss.), no se puede considerar correspondiente a los datos del derecho positivo aquel magisterio tradicional, autorizadamente confirmado, con carácter general, por MENGONI, L. "Autonomia privata e Costituzione». En Banca, borsa e titoli di credito, 1997, p. 9, según el cual, en el ordenamiento jurídico italiano, la buena fe tendría relevancia, exclusivamente, como regla de responsabilidad resarcitoria, cuya violación no podría incidir en la validez del negocio. Ya antes, por lo demás, dicho magiterio había sido radicalmente rechazado sobre la base de las orientaciones de la jurisprudencia (GALGANO, F. "Squilibrio contrattuale e mala fede del contraente forte». Contratto e impresa, 1997, p. 417 y ss., seguido por RICCIO, A. "La clausola generale di buona fede è, dunque, un limite generale all'autonomia contrattuale». Contratto e impresa, 1999, p. 21 y ss.; en sentido crítico, cfr. D'AMICO, G. "Regole di validità e di comportamento nella formazione del contratto». Op. cit., p. 44 y ss.; e id., "Regole di validità» e principio di correttezza nella formazione del contratto. Op. cit., p. 62 y ss.).

71 Al respecto, véase lo que anotamos infra, en este mismo acápite. 
así se manifestarían los síntomas de un recrudecimiento de la anteriormente vigente dicotomía entre el derecho civil y el derecho comercial, aunque con finalidades diferentes (favorecer a los consumidores) de aquellas que, otrora, la caracterizaban (favorecer a los empresarios). ${ }^{72}$

Hay que destacar, sin embargo, que la hipotética contraposición entre contratos (civiles) de los consumidores y contratos (comerciales) de los empresarios, al menos si es entendida como una bipartición exhaustiva, no es idónea, de ninguna manera, para formalizar conceptualmente la realidad normativa. Es más, ella hace perder la pista de esta última. Es falso que las reglas analizadas prevean contratos que se puedan calificar, propiamente, como «civiles» y también, como es obvio, que los contratos a los que ellas no son aplicables sean calificables, propiamente, como "comerciales».

En primer lugar, las regulaciones que nos ocupan jamás son aplicables a los contratos que deberían definirse, propiamente, como «civiles», es decir, a los contratos celebrados entre dos consumidores, porque ellas presuponen en todos los casos — como hemos anotado- que una parte actúe como comerciante profesional. Resulta hasta paradójico que sea este último requisito el que caracteriza, uniformemente, el ámbito subjetivo de aplicación de tales regulaciones, porque la circunstancia de que el contrato sea celebrado por un consumidor en sentido técnico no es requerido siempre sino solamente en la mayor parte de los casos. No pocas de las reglas indicadas, en efecto, tienen en cuenta los contratos celebrados por un comerciante profesional, con prescindencia de la circunstancia de que la contraparte —incluso si ha sido definida como «consumidor»— haya actuado o no en el ámbito de su propia y eventual actividad comercial profesional. ${ }^{73}$

La enfatización de la protección del consumidor como criterio explicativo de las regulaciones analizadas determina, entonces, una suerte de inversión conceptual. ${ }^{74}$ Los contratos que ellas toman en consideración no pueden,

72 ZENO-ZENCOVICH, V. «Il diritto europeo dei contratti (verso la distinzione fra "contratti commerciali» e "Contratti dei consumatori»)». Giurisprudenza italiana, 1993, IV, col. 69; seguido por BENACCHIO, G. A. Diritto privato della Comunità Europea. Padua, 1998, p. 314 y ss. Una óptica análoga es la que se sigue en un breve ensayo, cuyo título enfatiza la separación entre tal regulación y el principio de igualdad en sentido formal, que es calificado, en forma poco feliz, como "un mito» (nos referimos al trabajo de STELLA RICHTER, G. "Il tramonto di un mito: la legge uguale per tutti (dal diritto comune dei contratti al contratto dei consumatori)». Giustizia civile. 1997, II, p. 199 y ss.).

73 Es de mencionar, por ejemplo, el artículo 5 del decreto legislativo 111, del 17 de marzo de 1995, para la aplicación de la directiva 90/314/CEE, relativa a los viajes, vacaciones y programas "todo incluido». Al respecto, véase, por todos, DELLI PRISCOLI, L. "COnsumatore", "imprenditore debole" e principio di uguaglianza». Contratto e impresa/Europa. 2003, p. 751 y ss.

74 SIRENA, P. "La nuova disciplina delle clausole abusive nei contratti stipulati con i consumatori». Op. cit., p. 289. 
de ningún modo, calificarse como "civiles», por lo menos si así se les pretende distinguir de, o hasta contrataponer a, los contratos "comerciales», porque ellos también son contratos "comerciales» o «de empresa». ${ }^{75}$ Si nos remitimos a las categorías conceptuales de la tradición del derecho privado decimonónico, en particular los llamados "contratos de los consumidores» (o, por mejor decir, los "contratos con los consumidores») son de calificar como actos unilateralmente comerciales (los llamados «actos mixtos»).

Hay que destacar, por lo tanto, que, en el aspecto exclusivamente estructural, las regulaciones jurídicas aquí estudiadas son abstractamente asimilables al derecho de los actos empresariales. ${ }^{76} \mathrm{Si}$ ello no descarta que tales regulaciones se puedan formalizar, de todas maneras, en el derecho común de los contratos - atendiendo, de igual forma, a que en la parte general prevista en el Código Civil ya existen normas aplicables solamente a los actos realizados por un empresario (arts. 1330 y 1368, 2 . párrafo del Código Civil)_, ${ }^{77}$ se termina planteando el problema, paradójico, de si ellas pueden asimilarse, propiamente, al derecho comercial en sentido técnico y

75 Resulta significativo que una indicación en tal sentido se encuentre no solo en la doctrina del derecho mercantil, que ha afrontado más ampliamente el tema aquí señalado (BuOnOCORE, V. "Contratti del consumatore e contratti d'impresa». En P. Stanzione (ed.). La tutela del consumatore tra liberismo e solidarismo. Nápoles, 1999, p. 163; OPPO, G. "Note sulla contrattazione d'impresa». Op. cit., p. 629; GuIzzı, G. Op. cit., p. 125; y Delli PRISCOLI, L. Op. cit., p. 749), sino también en la doctrina del derecho civil (BESSONE, M. Imprese e società. Roma, Bari, 2001, p. 48; DI SABATO, D. "Contratti dei consumatori, contratti d'impresa». Rivista trimestrale di diritto e procedura civile, 1995, p. 657 y ss.).

76 Utilizando las categorías conceptuales forjadas por uno de los máximos estudiosos alemanes del derecho mercantil (SCHMIDT, K. "Vom Handelsrecht zum Unternehmensprivatrecht». En Juristische Schulung (JuS). 1985, p. 249; id. Handelsrecht. 4. ${ }^{a}$ ed. Colonia, 1994, p. 11 y ss.), el derecho europeo de los contratos puede ser caracterizado como un derecho "externo» de la empresa, o sea, como régimen de los actos empresariales (Unternehmenstransaktions- oder-außenrecht). Este derecho tiene a su lado, y se integra con, el derecho europeo de las sociedades, que constituye el derecho «interno» de la empresa, esto es, el régimen de la organización empresarial (Unternehmensorganisations-oder-innenrecht) (GRUNDMANN, S. Europäisches Schuldvertragsrecht Das europäische Recht der Unternehmensgeschäfte. Op. cit., p. 13).

77 BENEDETTI, G. Il diritto comune dei contratti contratti e degli atti unilaterali. Op. cit., p. 158; BUONOCORE, V. Contrattazione d'impresa e nuove categorie contrattuali. Milán, 2000, p. 121 y ss.; en su trabajo precedente, id. "I contratti d'impresa». En V. Buonocore, A. Luminoso et. al. Contratti d'impresa. Milán, 1993, p. 21 y ss.; y DI SABATO, D. Op. cit., p. 660 y ss. Según CIAN, G. "Diritto civile e diritto commerciale oltre il sistema dei codici». Rivista di diritto civile, 1974, I, p. 553, también el régimen de las cláusulas generales de contratación y de los contratos celebrados mediante modelos y formularios (arts. 1341 y 1342 del Código Civil), no obstante su formulación literal, debería considerarse, formalmente, como "comercialista», atendiendo a que la contratación en masa sería concebible, exclusivamente, en el ejercicio de una actividad empresarial (en tal sentido, si bien implícitamente, véase también BESSONE, M. Op. cit., p. 49). 
separarse, así —en oposición a la tesis doctrinal antes expuesta—, del derecho civil. ${ }^{78}$

A fin de dar una respuesta convincente y teóricamente fundada a dicha cuestión, el análisis estructural, por más necesario que sea, no es suficiente. Es menester tomar en consideración el aspecto funcional de las regulaciones en mención, ${ }^{79}$ es decir, la razón sustancial que, según el orden sistemático, justifica las normas jurídicas que forman parte de ellas.

$\mathrm{Al}$ respecto, conviene fijar una premisa: como alguien ha observado, ${ }^{80}$ la relación entre la regulación de los contratos celebrados por un comerciante profesional y por un consumidor (unilateralmente comerciales) y la regulación de los contratos celebrados entre dos comerciantes profesionales (bilateralmente comerciales) se ha invertido, en comparación con lo que establecía el antiguo Código de Comercio italiano. En el ámbito aplicativo de este Código, en efecto, se comprendían los contratos del primer género (que, en la actualidad, se llamarían "contratos de los consumidores»), con carácter predominante respecto del Código Civil. Tales contratos estaban sujetos a la misma regulación aplicable a los contratos bilateralmente comerciales (ar. 54).$^{81}$ De tal manera, invirtiendo su actitud inicialmente favorable a la

78 En general, y como ha sido verificado recientemente, las disputas en torno de la autonomía del derecho mercantil como sistema se han superado porque, con la codificación italiana de 1942, se realizó "la fundamental unidad del derecho privado, como derecho de la sociedad civil» (OPPO, G. "Principi». En V. Buonocore (dir.). Trattato di diritto commerciale. I/l. Turín, 2001, p. 37; e id. "Codice civile e diritto commerciale». Rivista di diritto civile, 1993, I, p. 225). Ello no descarta, por otro lado, que el derecho mercantil se pueda configurar, todavía, como una realidad normativa especial y, por lo tanto, como una categoría específica del derecho privado (véase, especialmente, CIAN, G. Op. cit., p. 523 y ss.; PORTALE. "Diritto privato comune e diritto privato dell'impresa». En 1882-1982 cento anni dal codice di commercio. Actas del congreso internacional académico celebrado en Taormina, del 4 al 6 de noviembre de 1982. Milán, 1984, p. 227 y ss.; así como los recientes ensayos de LIBONATI, B. "La categoria del diritto commerciale». Rivista delle società, 2002, p. 1 y ss.; BUTTARO, L. "L'autonomia del diritto commerciale». Rivista del diritto commerciale e del diritto generale delle obbligazioni, 2002, I, p. 421 y ss., quien incluso llega a sostener - aunque esto no sea de compartir-que "se debe seguir hablando de una perdurable autonomía y especialidad del derecho mercantil, en el sentido en que ello se entendía bajo el Código de Comercio», p. 431). Para una radical remeditación del problema, centrada en la relación entre el derecho estatal y el fenómeno de la llamada "globalización», véase, además, IRTI, N. Norma e luoghi. Problemi di geo-diritto. Roma, Bari, 2001, p. 85 y ss.; id. L'ordine giuridico del mercato. Op. cit., p. 86 y ss., 154 y ss.

79 Aquí retomamos, aunque en un contexto diverso, la directriz metodológica impartida, con carácter general, por PERLINGIERI, P. «Nuovi profili del contratto». Op. cit., p. 230 y ss.

80 CIAN, G. "Significato e lineamenti della riforma dello Schuldrecht tedesco». Rivista di diritto civile, 2003, I, p. 7; MENGONI, L. "Problemi di integrazione della disciplina dei "Contratti del consumatore» nel sistema del codice civile». Op. cit., p. 537 y ss.; ZENOZENCOVICH, V. Op. cit., col. 69.

81 Galgano, F. "Lex mercatoria». En Storia del diritto commerciale. Bolonia, 1993, p. 103. 
clase agrícola, el legislador aseguraba a los empresarios, incluso cuando estos contrataban con sujetos extraños al ejercicio de su actividad profesional, la aplicación de aquel conjunto de normas que había surgido, originalmente y como excepción al derecho común, para proteger, precisamente, sus intereses corporativos. La cuestión no se reducía, pues, a ampliar (desmesuradamente) el campo de aplicación del Código de Comercio: había que construir un derecho de los contratos basado en la preeminencia sistemática del interés empresarial sobre el de todo otro individuo o grupo social. ${ }^{82}$ Son por demás elocuentes las palabras anotadas por Vivante, casi con desconsuelo, en su célebre tratado: "Todo aquel que contrata con un comerciante debe estar sujeto a la ley del comerciante». ${ }^{83}$

En el derecho vigente, por el contrario, las regulaciones de los contratos celebrados por un consumidor no han servido para extender la aplicación de normas jurídicas que, precedentemente, reglamentaban solo los contratos entre comerciantes profesionales; ellas han servido, más bien, para introducir una diferenciación, que se caracteriza — como ya indicamos- por aquella protección de la autodeterminación económica del consumidor, que es necesaria a fin de impedir que el comerciante abuse del contrato. Pero dicha innovación no puede ser apreciada como una suerte de inversión dialéctica de la relación entre derecho civil y derecho comercial, al menos si así se pretende sugerir, de modo implícito, que ella hace prevalecer, sistemáticamente, el interés del consumidor por encima de la exigencia de objetiva «facilitación» de los intercambios comerciales, que constituye la perdurable especificidad — para lo que aquí interesadel ius mercatorum: la composición de los intereses contrapuestos de las partes contratantes, en efecto, queda siempre delegada al ejercicio de su autonomía negocial, ${ }^{84}$ que, en lo que respecta al comerciante profesional, es limitada por el legislador, en el sentido de evitar que aquel se aproveche, en violación del principio general de la buena fe, de la falencia del mercado. ${ }^{85}$

Así pues, las regulaciones que venimos analizando no pueden ser adscritas, sistemáticamente, al derecho mercantil en sentido estricto, porque su razón justificativa no consiste en la exigencia de introducir normas de excepción para facilitar la actividad empresarial. ${ }^{86}$ Ellas tampoco pueden ser

82 Ib., p. 103 y ss.

83 Citado por Galgano, F. Op. loc. ult. cit.

84 BARCELlona, P. Op. cit., p. 70.

85 Véase retro, $n .^{\circ} 2$.

86 Esta es, precisamente, la función del derecho mercantil en su concepción más evolucionada y, por decirlo así, "objetiva» (para un examen más exhaustivo, véase, por todos, OPPO, G. "Codice civile e diritto commerciale». Op. cit., p. 222, quien opina que la regulación de la "materia mercantil» estaría fundada en una doble razón socioeconómica: por un lado, la libertad de organización de la empresa y la rapidez y seguridad de la circulación; por otro lado, la confianza en el crédito). 
estimadas como índices normativos para contraponer al derecho común un derecho especial de los consumidores no solo porque su ámbito subjetivo presupone, necesariamente — contra lo que normalmente se cree-, que el contrato haya sido celebrado por un comerciante profesional, sino también, y sobre todo, porque su función sistemática consiste en restablecer la composición de los intereses en juego mediante el ejercicio de la autonomía negocial $^{87}$ cuando ello padezca impedimentos a causa de la falencia del mercado y, más específicamente, a causa de aquel particular paradigma del mercado, representado por las asimetrías informativas.

Se debe entender, entonces, que el presupuesto subjetivo de las regulaciones en mención, a pesar de constituir, evidentemente, un límite a su aplicabilidad, no es, en modo alguno, el criterio que ha de servir de base para la reconstrucción sistemática de ellas. ${ }^{88} \mathrm{La}$ asimetría informativa entre las partes contratantes, que constituye — como hemos anotado - el efecctivo problema que tales normas toman en consideración, no solo existe en las relaciones unilateralmente comerciales (business to consumer), sino también en las bilateralmente comerciales (business to business). ${ }^{89}$ No se trata, en efecto, de la debilidad o inexperiencia de algunas categorías o grupos de sujetos, sino de un

87 Es indudable que la realidad normativa que aquí nos ocupa, estructuralmente asimilada al régimen de los contratos empresariales, está caracterizada por una inversión de valores, en comparación con el modelo comercialista tradicional, porque ella, precisamente, no sirve ya para proteger el interés del empresario, sino el del consumidor. Así se reconfirma lo fecundo de la intuición según la cual aquello que es genéricamente definible como "derecho de la economía» puede orientarse hacia la protección de intereses sustanciales contrapuestos, que un análisis puramente estructural de las instituciones jurídicas, en cambio, no está en capacidad de identificar (ASCARELLI, T. "Teoria della concorrenza e interesse del consumatore». Rivista trimestrale di diritto e procedura civile, 1954, p. 936). Hay que precisar, empero, que dicho interés del consumidor no es identificado y protegido por el ordenamiento jurídico como interés especial o privilegiado, dialécticamente predominante en el de la contraparte, sino como interés general (al funcionamiento del mercado). En otras palabras, el consumidor "es, en último análisis, el miembro de la sociedad, indistinto, cuyo interés se considera general» (ASCARELLI, T. "Sviluppo storico del diritto commerciale e significato dell'unificazione». En id. Saggi di diritto commerciale. Milán, 1995, p. 18).

${ }^{88}$ En tal sentido, véase, ALESSI, R. Op. cit., p. 20; BENEDETTI, G. "Tutela del consumatore e autonomia contrattuale». Op. cit., p. 804; GABRIELLI, E. Op. cit., p. 1155 y sS.; IRTI, N. L'ordine giuridico del mercato. Op. cit., p. 44; ROPPO, V. II contratto del duemila. Op. cit., p. 53, especialmente 56. Asimismo, véase AZZARO, A. M. I contratti non negoziati. Nápoles, 2000, p. 104, 107. Para una perspectiva radicalmente contrapuesta, que ve en los estatus subjetivamente relevantes el criterio reconstructivo de las misma regulaciones, cfr., en cambio, ALPA. Status e capacità. La costruzione giuridica delle differenze individuali. Roma, Bari, 1993, p. 40 y ss.; LIPARI, N. "Il mercato: attività privata e regole giuridiche». Op. cit., p. 51; id., "Diritto e mercato della concorrenza». Op. cit., p. 36 y ss. Véanse también, al respecto, las indicaciones de Dosı, Klesta. "Lo status del consumatore: prospettive di diritto comparato». Rivista di diritto civile, 1997, II, p. 667 y ss.

89 Jannarelli, A. Op. cit., p. 63; RopPo, V. II contratto del duemila. Op. cit., p. 53 y ss. 
paradigma de falencia del mercado en cuanto tal, que constituye, es más, y paradójicamente, una consecuencia necesaria de aquel principio de división y de especialización del trabajo que, siguiendo a Adam Smith, es visto como uno de los presupuestos de eficiencia del mercado mismo. ${ }^{90}$

La decisión del legislador de limitar su intervención regulatoria solo a los contratos entre un empresario y un consumidor no es, por lo tanto, la expresión de una hipotética exigencia de proteger a este último como sujeto débil. ${ }^{11}$ En realidad, una exigencia semejante resulta secundaria y potencialmente desorientadora. ${ }^{92}$ Las razones justificadoras de tal intervención deben identificarse, más bien, en la peculiar conformación que el principio de subsidiariedad genera para las competencias legislativas de la Comunidad Europea, que existen dentro de ciertos límites, a saber: que se demuestre que su ejercicio es indispensable para el logro de los objetivos institucionales correspondientes. Y la certeza de que la eliminación de la asimetría informativa entre las partes contratantes es indispensable para la instauración y el funcionamiento del mercado único (que constituye, justamente, el objetivo institucional de la señalada intervención legislativa) existe solo para los contratos celebrados entre comerciantes profesionales y consumidores. ${ }^{93}$

En estos contratos, efectivamente, es donde las asimetrías informativas entre las partes comprometen, inevitablemente y estructuralmente, la eficiencia asignativa del mercado y, por lo tanto, el bienestar colectivo. ${ }^{94}$ En cambio, en los contratos entre dos empresarios tales asimetrías no son insuperables ni necesariamente dañosas. La "profesionalidad» del empresario representa, qué duda cabe, un motor permanente de conocimiento, gracias al cual él puede adquirir, en forma progresiva, las informaciones que son

90 GRUNDMANN, S. "Verbraucherrecht, Unternehmensrecht, Privatrecht - warum sind sich UN-Kaufrecht und EU-Kaufrechts-Richtlinie so ähnlich». Archiv für die civilistische Praxis, vol. 202, 2002, p. 68 y ss. En igual sentido, véase ROPPO, V. Il contratto del duemila. Op. cit., p. 42, quien opina que las normas aquí estudiadas resuelven el problema de los contratos económicamente desequilibrados, que se celebran en condiciones (no ya de patología, como ocurre en la rescisión por lesión o cuando media la incapacidad de entender y de querer, sino) de fisiología social.

91 La concepción del consumidor basada en su hipotética "condición estructural de inferioridad» siempre ha sido objeto de discusión, y ampliamente, en la bibliografía alemana (véanse las referencias de MICKLITZ, H. Op. cit., p. 636 y ss.).

92 Véanse las claras indicaciones de IRTI, N. L'ordine giuridico del mercato. Op. cit., $p$. 105; y GABRIELLI, E. Op. cit., p. 1157.

93 JANNARELLI, A. Op. cit., p. 37.

94 Véase, en tal sentido, lo que ya anotaba AKERLOF, G. "The Market for Lemons: Quality Uncertainty and the Market Mechanism». Quarterly Journal of Economics, vol. 84, 1970, p. 488 y ss. 
útiles para evaluar la conveniencia de todo contrato celebrado en el marco de su actividad económica. Es más, el aprovechamiento de la distribución desigual de las informaciones entre los empresarios competidores constituye, usualmente, un incentivo fundamental para la iniciativa económica. Por tal motivo, la eliminación indiscriminada de toda asimetría informativa en los contratos bilateralmente comerciales podría resultar innecesaria, y hasta perjudicial, en concreto, para el bienestar colectivo.

Lo anterior explica por qué las transacciones del primer tipo (unilateralmente comerciales) han sido exhaustivamente reguladas por normas específicas, mientras que las del segundo tipo (bilateralmente comerciales) han sido reguladas de manera mucho más limitada. La impresión que se genera es que las nuevas reglas, que son objeto del presente estudio, se explican, propiamente, desde la perspectiva de la posición del consumidor. Sin embargo, la particularidad del ámbito subjetivo de aplicación de ellas se presenta — como hemos anotado- contingente y extrínseca, atendiendo a la realidad normativa que las caracteriza: ${ }^{95}$ para ser precisos, dichas regulaciones no tienen como fin el hacer prevalecer el interés de una u otra de las partes contratantes (ni el del consumidor ni el del comerciante profesional), sino la protección del interés general en funcionamiento del mercado. ${ }^{96}$

Estamos, por lo tanto, ante normas que no pueden ser asimiladas ni al derecho mercantil ni al derecho de los consumidores. Se trata de normas

95 Este dato, considerado por sí solo, no es válido, ciertamente, para descartar la vinculación de dichas regulaciones con la parte general, ya que esta última comprende, desde siempre, disposiciones no aplicables a todo contrato (así opina VITUCCI, P. Op. cit., p. 808, quien deriva, sin embargo, en contra del planteamiento aquí seguido, un juicio de incoherencia teórica y de ineficiencia práctica de la propia parte general del contrato; en este último sentido, véase también NOVA, G. de. "Sul rapporto tra disciplina generale dei contratti e disciplina dei singoli contratti». Op. cit., p. 328 y ss.; id. "I singoli contratti: dal titolo III del libro IV del codice civile alla disciplina attuale». Op. cit., p. 488 y ss., quien, partiendo de la constatación de que las normas de parte especial crean, a veces, excepciones a las normas de parte general, arriba a la conclusión de que esta última es aplicable solo con carácter residual, porque el régimen aplicable a los contratos en particular debería ser identificado, prioritariamente, en las disposiciones de la parte especial).

96 Véase, por ejemplo, ASCARELLI, T.. Teoria della concorrenza e interesse del consumatore. Op. cit., p. 935 y ss., de quien merece ser citada una memorable consideración, relativa a la evolución y a la esencia del derecho mercantil: "La fuerza del derecho mercantil se encuentra, precisamente, en la capacidad con la cual ha superado su original carácter clasista, al volverse derecho estatal, ya con el mercantilismo, y pasando, luego, con el sistema objetivo, a dictar reglas aplicables a todos, y creando instituciones y principios que a la larga han devenido de derecho común, en tanto orientados hacia un general progreso técnico y económico, y no a la protección de particulares intereses» (las cursivas son añadidas). Para una amplia reflexión sobre el papel desarrollado por la cultura jurídica italiana, véase LIBONATI, B. "Diritto commerciale e mercato (L'insegnamento di Tullio Ascarelli)». En Diritto privato, 1997. T. III: "L'abuso del diritto». Padua, 1998, p. 551 y ss. 
que se integran al derecho privado en general $^{97} \mathrm{y}$, específicamente, al derecho general de los contratos. ${ }^{98}$

\section{Sigue: los nuevos procedimientos de formación del acuerdo}

La pertenencia de las regulaciones que venimos analizado al derecho general de los contratos topa con otro inconveniente: la delimitación de sus presupuestos objetivos de aplicación, los cuales parecen imprimirles un carácter de particular especialidad, debido, asimismo, a que corresponden, a veces, a fenómenos socioeconómicos que podrían considerarse marginales en el ámbito de la actual realidad fáctica.

Pero, una vez más, la percepción de fragmentariedad parece originada, sobre todo, por la impropia, e instintiva, asunción del derecho tradicional de los contratos - tal cual este se ha formado, históricamente, en los distintos ordenamientos jurídicos nacionales - como modelo de parangón y cotejo de las nuevas regulaciones, las cuales, por el contrario, al haber sido introducidas por el derecho comunitario, se basan en presupuestos sistemáticos y técnicas legislativas radicalmente diversas.

Como ya hemos subrayado, la peculiar delimitación de la competencia legislativa de la Comunidad Europea para armonizar los ordenamientos jurídicos nacionales comporta, necesariamente, que el derecho europeo de los contratos se limite a prever las normas jurídicas indispensables para remediar las falencias del mercado. Así pues, tales normas no pueden hacer otra cosa que regular supuestos netamente específicos y, por decirlo así, «anormales», dado que se asume, en la estrategia de política del derecho que constituye la base del ordenamiento comunitario, que el mercado está,

97 En otras palabras, en el derecho civil, si este último es entendido no ya como "conjunto de las normas y de los principios jurídicos que se refieren al civis, considerado al margen de su eventual dimensión de homo oeconomicus», sino como "summa y ciencia de los principios y de las reglas que deben ser válidas como comunes elementos de base, como tejido conector [...] para todos los sectores del derecho privado» (CIAN, G. "Il diritto civile come diritto privato comune». En La civilistica italiana dagli anni '50 ad oggi tra crisi dogmatica e riforme legislative. Padua, 1991, p. 12 y ss.).

98 GRUNDMANN, S. "Verbraucherrecht, Unternehmensrecht, Privatrecht - warum sind sich UN-Kaufrecht und EU-Kaufrechts-Richtlinie so ähnlich». Op. cit., p. 43 y ss. Con el recurso a una paradoja eficaz, se ha afirmado que el régimen de los artículos 1469-bis y ss. del Código Civil es "encuadrable como parte especial del régimen general de los contratos» (BUSNELLI, F. D. Op. cit., p. 548). La concepción opuesta, según la cual se trataría, más bien, de un derecho especial, se ha afirmado, como es sabido, en la experiencia jurídica francesa (véase, por todos, CALAIS-AUlOY, J. "L'influence du droit de la consommation sur le droit civil de contrats». Revue trimestrielle de droit civil, 1994, p. 239 y ss., especialmente 253 y ss.). 
generalmente, en condición de asegurar, por sí mismo, el logro de la eficiencia en la asignación de recursos, de modo que no sería necesaria ninguna intervención legislativa regulatoria. Esta última premisa no es nada extraña a la tradición de los ordenamientos jurídicos nacionales, que, al no sufrir ninguna limitación de soberanía basada en el principio de proporcionalidad, tampoco derivan de ella una restricción del derecho de los contratos - como la verificada en el ordenamiento comunitario—, sino más bien, y solamente, una específica conformación de tal derecho. En su mayor parte, en efecto, el derecho de los contratos está constituido por normas jurídicas dispositivas que, por presuponer, precisamente, que el mercado está en condición de funcionar de manera automática, apuntan únicamente a facilitar el ejercicio de la autonomía contractual de las partes. En cambio, las específicas y anómalas situaciones de falencia del mercado se encuentran reglamentadas, inevitablemente, por (pocas) normas que no admiten excepciones.

También hemos indicado que el derecho comunitario de los contratos puede prever solamente las normas del segundo tipo, porque estas son las únicas indispensables para el funcionamiento del mercado, y se comprenden, por lo tanto, sobre la base del principio de subsidiariedad, en la correspondiente competencia legislativa de la Comunidad Europea. En consecuencia, el derecho comunitario de los contratos resulta más limitado, constitutivamente, que el derecho nacional, aunque no sea dado considerarlo fragmentario, ya que, en la actualidad, regula prácticamente por completo todos los (pocos) casos de falencia del mercado único.

Por otro lado, es necesario considerar que, desde el punto de vista que aquí nos interesa, el derecho comunitario de los contratos (celebrados por los consumidores) puede subdividirse en dos partes distintas, ${ }^{99}$ que pueden calificarse como "general» y «especial», respectivamente.

Algunas de las regulaciones bajo examen son respectivamente aplicables, en efecto, solo a una determinada categoría tipológica de contratos celebrados entre un profesional y un consumidor, cuyo criterio unificante, desde el punto de vista formal, no está constituido, salvo en raros casos (por ejemplo, en la llamada venta de paquetes turísticos «todo incluido»), por el tipo de contrato celebrado, sino por el tipo de actividad empresarial que el profesional ejerce mediante la celebración del contrato (por ejemplo, la prestación de servicios financieros o bancarios). Si bien este último criterio de tipificación contractual es bastante extraño a la tradición de nuestro

99 GrundmanN, S. "La struttura del diritto europeo dei contratti». Op. cit., p. 384 y ss.; ROPPO, V. Il contratto del duemila. Op. cit., p. 26 y ss. 
derecho nacional, ${ }^{100}$ se puede afirmar, por lo tanto, que dichas regulaciones del contrato resultan particulares, en el sentido de los artículos 1322, 2. ${ }^{\circ}$ párrafo, y 1323 del Código Civil, y que corresponden, por consiguiente, a aquella "parte especial» del derecho de los contratos que se encuentra prevista en los artículos 1470 y ss. del Código Civil. ${ }^{101}$

Por el contrario, hay otras regulaciones que son aplicables a todo contrato celebrado entre un profesional y un consumidor, al margen de un determinado criterio de caracterización tipológica (del contrato mismo o de la actividad empresarial). ${ }^{102}$ Sus presupuestos de aplicación identifican, en cambio, una peculiar modalidad de negociación y de celebración del contrato (por ejemplo, los contratos celebrados «fuera de los locales comerciales», «a distancia», «a través de instrumentos telemáticos», etc.), ${ }^{103}$ la cual, por sus propias características intrínsecas, es susceptible de determinar la falencia del mercado a causa de la evidente y grave asimetría informativa entre las partes. La formalización de dicha realidad normativa no puede ser convenientemente elaborada si se emplea el concepto de "procedimiento", tal cual este ha sido definido, en general, por la doctrina que ha prestado mayor atención al tema de la celebración del contrato, ${ }^{104}$ a saber: como configuración de varios y multiformes actos, técnicamente calificables como prenegociales, que, considerados en cuanto tales, no se identifican, en modo alguno, en la figura contractual, sino que se agotan, íntegramente, en su predisposición. ${ }^{105}$ Puesto que — como, autorizadamente, se ha destacado- ${ }^{106}$ "la variedad de los procedimientos no compromete la unidad, sino que la realza, más bien, de la misma forma que la unidad no descarta las distinciones en su interior», la especificidad de las regulaciones aquí analizadas, por

100 Al respecto, se ha hablado de "grupos de contratos» (NOVA, G. de. "I singoli contratti: dal titolo III del libro IV del codice civile alla disciplina attuale». Op. cit., p. 499 y ss.; id., "Contratto: per una voce». Op. cit., p. 655 y ss.; seguido por BUONOCORE, V. Contrattazione d'impresa e nuove categorie contrattuali. Op. cit., p. 76).

101 Según Nova, G. de. "I singoli contratti: dal titolo III del libro IV del codice civile alla disciplina attuale». Op. cit., p. 499 y ss., se trataría de "una serie de segmentos de disposiciones generales, que se ubican en un nivel intermedio entre el régimen del contrato en general y el régimen de los contratos en particular».

102 ZENO-ZENCOVICH, V. Op. cit., col. 59.

103 BENEDETTI, G. "Tutela del consumatore e autonomia contrattuale». Op. cit., p. 809; BUONOCORE, V. "Contratti del consumatore e contratti d'impresa». Op. cit., p. 121 y ss.

104 BENEDETTI, G. Dal contratto al negozio unilaterale. Milán, 1969, p. 52 y sS.

105 Sobre la naturaleza de los actos prenegociales, véase SANTORO-PASSARELLI, F. Dottrine generali del diritto civile. 9. ${ }^{2}$ ed. Nápoles, 1989 (reimpresión), p. 209 y ss., sometido a reflexión por el propio autor en BENEDETTI, G. Dal contratto al negozio unilaterale. Op. cit., p. 53 (nota 62).

106 BenEDETtI,G. Il diritto comune dei contratti e degli atti unilaterali. Op. cit., p. 42. 
más marcada que sea, no quita que ellas dicten normas generales a la cuales, en el sentido del artículo 1323 del Código Civil, quedan sometidos «todos los contratos».

En el ámbito de la bipartición fundamental que acabamos de identificar, en la cual no se puede evitar reconocer — como habíamos adelantadolos signos de la dialéctica tradicional entre "parte general» y "parte especial» del derecho de los contratos, una ubicación particular, que podría definirse «intermedia», es la que corresponde asignar a la regulación de la venta de bienes de consumo (art. 1519-bis y ss. del Código Civil). Atendiendo, en efecto, a la reconocida idoneidad de dicho tipo contractual para constituir el paradigma de todos los contratos con efectos traslativos, su regulación, a pesar de no poder adscribirse, formalmente, a la "parte general», es asimilable a esta última en lo sustancial, porque prevé los remedios a los que puede recurrir, en general, el adquirente de un bien debido la violación del compromiso traslativo por parte del enajenante.

\section{Algunos corolarios: la (limitada) aplicabilidad analógica de las nue- vas normas a los contratos celebrados entre comerciantes profe- sionales}

Si las regulaciones aquí estudiadas, o por lo menos algunas de ellas, deben integrarse, pues, en la parte general del derecho contractual, es inevitable interrogarse sobre la aplicabilidad de ellas a los contratos celebrados por partes que no satisfagan los requisitos subjetivos expresamente previstos por el legislador. Aquí se plantea, en particular, el problema de establecer si ellas son aplicables a los contratos celebrados entre empresarios. ${ }^{107}$

Es conveniente destacar, de inmediato, que las normas destinadas a eliminar la asimetría informativa entre las partes contratantes son eficientes, sin más, solo en lo que atañe a los contratos unilateralmente comerciales; en cambio, lo son solo a veces en lo que atañe a los contratos bilateralmente comerciales.

La consecuencia de lo anterior en el plano de los efectos, y sobre la base del principio de subsidiariedad, es una limitación de la competencia legislativa atribuida, en materia, a la Comunidad Europea. Por lo tanto, resulta del todo coherente y digno de aprobación la tendencia del Tribunal de Justicia de las Comunidades Europeas, que ha descartado, repetidamente, toda aplicación de las directivas que nos ocupan más allá de la definición

107 JANNARELLI, A. Op. cit., p. 67 y sS. 
legislativa del consumidor como persona física que actúa al margen de su propia y eventual actividad «profesional». ${ }^{108}$

En cambio, en lo concerniente a cada ordenamiento jurídico nacional, nada impide, en principio, que la aplicabilidad de dichas regulaciones se extienda gradualmente a los contratos celebrados entre empresarios, ${ }^{109}$ siempre y cuando se detecte aquella misma exigencia de protección que ha sido acogida por el legislador. Esta última condición se presenta, en particular, en lo tocante al control del carácter abusivo de las cláusulas generales de contratación. ${ }^{110}$

No es casual, por otro lado, que ya con anterioridad a la aplicación en el ordenamiento jurídico italiano de la directiva comunitaria en materia la doctrina haya lamentado la inaplicabilidad de la nueva regulación para la protección de aquella parte contratante que, a pesar de celebrar el contrato en el marco de su propia actividad profesional, se encuentre, de todos modos, y típicamente, en una situación de debilidad socioeconómica análoga a la del consumidor, en especial cuando se trate de una entidad jurídica sin fines de lucro o de un pequeño empresario, en el sentido del artículo 2083 del Código Civil. ${ }^{111}$ La jurisprudencia de las instancias de mérito, por su parte, al considerar que la superación de tales límites no es permitida, positivamente, por las normas dictadas en los artículos 1469-bis y ss. del Código Civil, no ha evitado formular, amparándose en los artículos 3, 35 y 41 de la Constitución de la República Italiana, la cuestión de la legitimidad

108 Para referencias detalladas al respecto, véase BARCA, A. "Brevi note in ordine alla nozione di consumatore». La Nuova giurisprudenza civile commentata, 2003, II, p. 367 y ss.; MeNGOzZI. "La nozione di consumatore, la direttiva 93/13 ed il diritto italiano». Contratto e impresa/Europa, 2002, p. 54 y ss.

109 En un sentido que tiende a ser favorable a dicha perspectiva, véase ALESSI, R. Op. cit., p. 39. Es relevante que una posición análoga, si bien en el ámbito de planteamientos distintos desde el punto de vista conceptual y también político, haya sido expresada por los defensores de las concepciones solidaristas del derecho europeo de los contratos (véase WilhelmSSON, T. Social Contract Law and European Integration. Op. cit., p. 35, 163 y ss.; SommA, A. II diritto dei consumatori. Op. cit., p. 683, 686; id. "Il diritto privato liberista. A proposito di un recente contributo in tema di autonomia contrattuale». Op. cit., p. 293 y ss.).

110 Véase, al respecto, el amplio estudio de GATT, L. Commentario sub art. 1469-bis, 2. ${ }^{\circ}$ párrafo del Código Civil. En Commentario al capo XIV bis del codice civile: dei contratti del consumatore. Op. cit., p. 803 y ss.

111 Véase, por todos, OРPO, G. «Presentazione». En Le clausole abusive nei contratti stipulati con i consumatori. Op. cit., p. 7; id. "Note sulla contrattazione d'impresa». Op. cit., p. 637; id. «Impresa e mercato». Op. cit., p. 427. 
constitucional de tales artículos, ${ }^{112}$ la cual, sin embargo, ha sido declarada infundada por la Corte Costituzionale. ${ }^{113}$

Aun cuando infructuosos, tales intentos responden, qué duda cabe, a efectivas exigencias sustanciales, las cuales, sin embargo, justamente por no ser incoherentes, en modo alguno, con los datos del derecho positivo, pueden ser satisfechas con una adecuada interpretación de las disposiciones ahora examinadas y su consiguiente aplicación analógica. ${ }^{114}$ Si la «voluntad

112 La cuestión de legitimidad constitucional fue interpuesta, por primera vez, por el Giudice di Pace dell'Aquila (decreto del 3 de noviembre de 1997, publicado en Giustizia civile, 1998, I, p. 2341 y ss., con comentario de GATT, L. "L'ambito soggettivo di applicazione della normativa sulle clausole vessatorie»), pero fue declarada manifiestamente inadmisible por ausencia de fundamentos en orden a su relevancia, porque el contrato objeto de la controversia había sido celebrado con anterioridad a la entrada en vigor de los artículos 1469-bis y ss. del Código Civil (Corte Costituzionale, sentencia 282, del 30 de junio de 1999. En Giustizia civile, 2000, I, p. 1928 y ss.; en II Foro italiano, 1999, I, col. 3118 y ss., con comentario de PALMIERI, A. "L'ibrida definizione di consumatore e $i$ beneficiari (talvolta pretermessi) degli strumenti di riequilibrio contrattuale»; y en Giurisprudenza costituzionale, 1999, p. 2296 y ss.).

113 Corte Costituzionale, sentencia 469, del 22 de noviembre del 2002, en II Foro italiano, 2003, col. 332 y ss., con comentarios de PALMIERI, A. "Consumatori, clausole abusive e imperativo di razionalità della legge: il diritto privato europeo conquista la Corte Costituzionale»; y de PLAIA, A. "Nozione di consumatore, dinamismo concorrenziale e integrazione comunitaria del parametro di costituzionalità». En I contratti. 2003, p. 653 y ss., con comentario de Capilli. El decreto que contenía la cuestión de legitimidad provino del Giudice di pace Sanremo, decreto del 5 julio 1999, publicado en Giurisprudenza di merito, 2002, p. 649 y ss. Al respecto, cfr. las contrapuestas opiniones de CALVO, R. «Il concetto di consumatore, l'argomento naturalistico ed il sonno della ragione». En Contratto e impresa/Europa, 2003, p. 715 y ss.; y de DeLLI PRISCOLI, L. Op. cit., p. 749 y ss. Desde una perspectiva diversa y reciente, se ha sostenido que el artículo 1469-bis del Código Civil viola el artículo 3 de la Constitución, porque «no incluye en la noción de consumidor al beneficiario, no contratante, de la póliza acumulativa en caso de accidentes, contratada por el empleador» (Tribunale di Napoli, sentencia del 22 de julio del 2002. Il Foro italiano, 2003, I, col. 336 y ss.).

114 Cfr., sin embargo, en sentido contrario, D'AMICO, G. "Regole di validità e di comportamento nella formazione del contratto». Op. cit., p. 48 y ss.; y, más ampliamente, ROPPO, V. «Il contratto». Op. cit., p. 912, quien presta atención al problema de la protección contractual del comerciante profesional "débil» y destaca que dicho problema ha sido resuelto, en todo caso, por la ley sobre el subaprovisionamiento (ley 192, del 18 de junio de 1998). Hay que destacar, sin embargo, que este último régimen jurídico, en lo tocante, especialmente, a la prohibición de abuso de dependencia económica, no concierne (para retomar la distinción terminológica formulada por el propio Roppo en su obra II contratto del duemila. Op. cit., p. 42 y ss.) al fenómeno "fisiológico» de las asimetrías informativas entre las partes contratantes, sino al fenómeno "patológico» de la limitación de la libertad contractual de una de ellas a causa de la concentración de poder económico de la otra (véase también GABRIELLI, E. Op. cit., p. 1181 y ss.; DELLI PRISCOLI, L. Op. cit., p. 760 y ss.). Se trata, por lo tanto, de una temática sustancialmente vinculable con una específica configuración de la prohibición antitrust del abuso de posición de dominio, tal cual ha sido confirmado, por lo demás, por la modificación que el decreto legislativo 231, del 9 de octubre del 2002, artículos 10 y 11, ha hecho de la ley en materia; se ha atribuido, además, en el nuevo párrafo 3-bis del artículo 9, significativas 
del legislador» es proteger al (consumidor, en tanto y en cuanto) adherente que se encuentra en una situación típica de debilidad socioeconómica frente al comerciante profesional predisponente, no se puede negar que la misma exigencia también se presenta cuando tal adherente es un comerciante profesional o un ente análogamente "débil». ${ }^{115}$

Pero esta conclusión interpretativa, por más innovativa y de compartir que sea, valoriza solo parcialmente la potencialidad normativa de las normas que ahora nos ocupan, porque resulta condicionada por la premisa según la cual ellas remediarían la patológica situación de debilidad socioeconómica de una parte del contrato frente a la otra. ${ }^{116}$

En cambio, si se concuerda en que hay que identificar la razón sustancial de dichas normas en la eliminación de aquellas (fisiológicas) asimetrías informativas entre las partes contratantes, que determinan la falencia del mercado, se debe admitir coherentemente que el problema de su aplicabilidad se plantea frente a todo aquel que se adhiera a las cláusulas generales de contratación (predispuestas por un empresario), independientemente del hecho de que se trate de un sujeto que actúa en calidad de consumidor o de empresario. La predisposición de cláusulas generales de contratación crea, en efecto, una suerte de «monopolio de hecho» del empresario, sobre la información jurídicamente relevante, que la eventual experiencia profesional de la otra parte contratante no es suficiente, normalmente, para superar si no es con la asunción de costos de transacción desproporcionados. La ignorancia del adherente con respecto al contenido de las condiciones de contrato no puede considerarse una circunstancia excepcional, ligada, por ejemplo, a las escasas capacidades profesionales del sujeto o bien a la ausencia de una organización adecuada, sino que tiende a transformarse — como

competencias de investigación y de sanción del abuso para la Autorità Garante della Concorrenza e del Mercato (véase, en general, MAUGERI. "Le recenti modifiche della disciplina dell'abuso di dipendenza economica in una prospettiva comparatistica». En Europa e diritto privato, 2002, p. 455 y ss.; y, más ampliamente, de la misma autora, Abuso di dipendenza economica e autonomia privata. Milán, 2003, p. 8 y ss.).

115 Para una expresa, aun cuando problemática, indicación en tal sentido, véase, BUSNELLI, F. D. "Note in tema di buona fede ed equità». Op. cit., p. 548 y ss. y p. 552, quien considera que el papel de regla-criterio general del artículo 1469-bis, 1. ${ }^{\circ}$ párrafo, del Código Civil, combinándose con el valor general de las normas sobre la buena fe en la parte general del contrato, "podría legitimar una apertura más o menos directa y extendida a los "no consumidores débiles» de la regulación en cuestión. Particular importancia, en tal sentido, es la que atribuye el autor citado al artículo 1366 del Código Civil, para lo cual concede valor a una línea de pensamiento de BIGLIAZZI-GERI, L. "A proposito della proposta di attuazione della direttiva comunitaria sulle clausole abusive nei contratti stipulati con $i$ consumatori». En Le clausole abusive nei contratti stipulati con $i$ consumatori. Op. cit., p. 324 y ss.

116 Véase retro, $n .^{\circ} 4$. 
alguien ha destacado- ${ }^{117}$ en un fenómeno social propiamente dicho, que, en tanto permite a los operadores del mercado gozar de los beneficios de las economías de escala, ligadas, ni más ni menos, con la estandarización, responde a una determinada racionalidad (la llamada «racionalidad limitada»). ${ }^{118}$ Por lo tanto, la asimetría informativa entre las partes contratantes es estructural, al margen de la circunstancia de que el adherente actúe en calidad de consumidor o de comerciante profesional.

Una importante apertura en tal sentido se puede apreciar en una sentencia del Tribunale di Roma, la cual, de conformidad con la orientación de la jurisprudencia francesa, ${ }^{119}$ ha dictaminado que, "para efectos de establecer si el contratante ha obrado "por fines extraños a la actividad empresarial o profesional eventualmente cumplida», es menester verificar si la celebración de dicho contrato es o no un acto de la profesión del que adquiere el bien o el servicio, tal cual lo es para su contraparte». ${ }^{120}$ El principio de

117 BIANCA, C. M. "Presentazione» (anteriormente en su edición Le condizioni generali di contratto. I. Milán, 1979; y ahora) en Id. Realtà sociale ed effettività della norma. II/1. Op. cit., p. 398.

118 GABRIELLI, E. Op. cit., p. 1178 y ss.; PARDOLESI, R. y A. PACCES. "Clausole vessatorie e analisi economica del diritto: note in margine alle ragioni (ed alle incongruenze) della nuova disciplina». En Diritto privato. 1996. T. II: "Condizioni generali e clausole vessatorie». Padua, 1997, p. 397 y ss. Acerca del concepto de bounded rationality, ampliamente utilizado por el análisis económico del derecho, sigue siendo fundamental el estudio de SIMON, H. A. Models of Man. Nueva York, 1957. Sobre la base de dicho modelo, el homo oeconomicus no puede, en realidad, perseguir la maximización egoísta de su propio bienestar (la llamada «first-best solution»), porque ello resulta potencialmente impedido por la existencia de costos de transacción. En lo que atañe a la búsqueda y elaboración de las informaciones, en particular, las decisiones de aquel son, por lo tanto, solo limitadamente (racionales, y por ello) óptimas (la llamada "second best solution»). Sobre dichas premisas, justamente, se justifica, desde el punto de vista económico, la protección contractual del consumidor (véase, sobre todo, DUGGAN. "The Economics of Consumer Protection: A Critique of the Chicago School Case Against Intervention". Adelaide Law Review, Research Paper n. ${ }^{\circ}$ 2, Adelaida, 1982, p. 103 y ss.).

119 La solución según la cual el régimen contractual de protección del consumidor sería aplicable a todo comerciante profesional contratante que, frente a la contraparte, se encuentre en una análoga situación de debilidad ha sido reconocida por la Cour de Cassation, a partir de la sentencia de su 1. ${ }^{\text {ra }}$ Sala Civil, del 28 de abril de 1987, publicada en Juris-Classeur Périodique, 1987, II, 20893, con comentario de Paisant (al respecto, véase, GHESTIN y MARCHESSAUX. "L'applicazione in Francia della direttiva rivolta ad eliminare le clausole abusive». Trad. italiana de Coraggio. En Le clausole abusive nei contratti stipulati con i consumatori. Op. cit., p. 58 y ss.; CALAIS-AUlOY, J. Op. cit., p. 253 yss.).

120 Tribunale di Roma, sentencia del 20 de octubre de 1999, en Giustizia civile, 2000, I, p. 2117 y ss, con comentario (favorable) de COREA, U. "Ancora in tema di "consumatore» e contratti a scopi professionali: un intervento chiarificatore»; en I contratti, 2000, p. 442 y ss., con comentario (contrario) de Maffeis. En tal sentido, véase lo que ya había señalado (si bien en un obiter dictum, entre sus fundamentos) el Pretore di Foggia-Orta Nova, sentencia del 17 de diciembre de 1998, en Giurisprudenza italiana, 2000, p. 312 
derecho aplicado por lo jueces basa la existencia de una asimetría informativa entre las partes, entonces, en la ajenidad de la prestación o del servicio contractual a la específica competencia profesional del adherente —en los fundamentos de la sentencia citada se afirma, por ejemplo: «No se aprecia en qué sentido pueden ser diferentes la posición del representante comercial que adquiere un automóvil para su trabajo y la posición de otra persona (si no la de él mismo) [¿?] que lo adquiere para su familia»—. ${ }^{121}$ Se trata, sin embargo, de una solución que, a pesar de conducir a resultados prácticos concretamente apreciables, continúa resultando parcial.

En el supuesto de la predisposición unilateral de cláusulas contractuales estandarizadas, efectivamente, la asimetría informativa entre las partes es intrínseca al procedimiento mismo de formación del acuerdo, independientemente de la relación del específico contenido del contrato con la eventual actividad profesional del adherente. En principio, por lo tanto, parece perfectamente justificado que la regulación analizada, en la parte donde prevé un específico subrégimen normativo de las cláusulas generales de contratación, ${ }^{122}$

y sS., con comentario de TORRESI, T. "Consumatore, professionista. Fermenti giurisprudenziali»; y, posteriormente, el Giudice di pace di Civitanova Marche, sentencia del 4 de diciembre del 2001, en Giurisprudenza di merito, 2002, p. 654 y ss. Según un criterio más blando, la jurisprudencia de las instancias de mérito ha establecido también que los artículos 1469-bis y ss. del Código Civil son aplicables a los contratos celebrados (no ya en el ejercicio, sino) en vista de una actividad comercial profesional futura (Tribunale di Terni, sentencia del 13 de julio de 1999. En Danno e responsabilità., 2000, p. 862 y ss., con comentario de Palmieri; en el mismo sentido, y en relación con el decreto legislativo 50, del 15 de enero de 1992, véase Tribunale di Ivrea, sentencia del 5 de octubre de 1999, en la misma revista). Dichas tendencias interpretativas han sido contradichas por la Corte di Cassazione (sentencia 10127, del 25 de julio del 2001, en La Nuova giurisprudenza civile commentata, 2002, I, p. 630 y ss., con comentario de RINALDI, R. "Incompatibilità tra la nozione di consumatore e quella di professionista debole»; en I contratti, 2002, p. 338 y ss., con comentario de Caserta), que ha afirmado la siguiente máxima jurisprudencial: "Para que se presente la figura del "comerciante profesional» no es necesario que el contrato tenga lugar en el ejercicio de la actividad propia de la empresa o de la profesión; es suficiente que el contrato se efectúe para un fin vinculado con el ejercicio de la actividad empresarial o profesional»).

121 Dicho planteamiento conceptual es compartido, sustancialmente, por GABRIELLI, E. Op. cit., p. 1180 y ss., quien sostiene, precisamente, que la regulación aquí estudiada es aplicable a los "actos relativos a la profesión", siempre que ellos se presenten, respecto de esta última, en una relación de instrumentalidad ocasional (sería inaplicable, en cambio, cuando ellos sean realizados de manera no ocasional, además, como es obvio, de cuando se trate de "actos de la profesión»). Sin embargo, ello sería válido, exclusivamente, cuando el comerciante profesional sea una persona física y no, en cambio, cuando sea un ente, partiendo del presupuesto de que la "profesionalidad» de este último "constituye, de por sí, un factor impeditivo (o cuando menos fuertemente reductivo) del deficit informativo en el acto de consumo» (p. 1181).

122 Sobre la identificación de dicho subconjunto de normas, véase, en general, y con especial referencia al artículo 1469-sexies del Código Civil, ROPPO, V. "La nuova disciplina delle clausole abusive nei contratti fra imprese e consumatori». En E. Cesàro (ed.). 
sea susceptible de aplicación analógica a los contratos celebrados entre comerciantes profesionales. ${ }^{123}$

Dicha conclusión tiene a su favor un fundamento constitucional: el artículo 41, 2. ${ }^{\circ}$ párrafo de la Constitución, el cual —admitiendo su aplicabili$\mathrm{dad}$ a las relaciones horizontales - ${ }^{124}$ no puede hacer referencia sino a las relaciones entre empresarios y, por igual, a las relaciones entre empresarios y consumidores. ${ }^{125}$

Clausole abusive e direttiva comunitaria. Padua, 1994, p. 88, 91; NAPOLITANO, A. y V. ROPPO. "Clausole abusive». En Enciclopedia giuridica Treccani. Apéndice de actualización. Vol. III. Roma, 1994, p. 1 y sS., 6 (de la separata); BUSNELLI, F. D. y U. MORELLO. "La direttiva 93/13/CEE del 5 aprile 1993 sulle clausole abusive nei contratti stipulati con i consumatori». Rivista del notariato, 1995, p. 370; SCOGNAMIGLIO, C. "Principi generali e disciplina speciale nell'interpretazione dei contratti dei consumatori». Rivista del diritto commerciale e del diritto generale delle obbligazioni, 1997, I, p. 953 y ss.; TUCCI. "Clausole vessatorie o abusive e disciplina dei contratti di investimento». Rassegna di diritto civile, 1999, p. 149; MONTICELLI. "Commentario sub art. 1469-ter». En E. Cesàro (ed.). Clausole vessatorie e contratto del consumatore. 2. ${ }^{a}$ ed. Milán, 1998, pp. 507, 527 y 531; CAPOBIANCO, E. "La nuova disciplina delle clausole vessatorie nei contratti con $i$ consumatori (artt. 1469 bis-1469 sexies c. c.)». Vita notarile, 1996, pp. 1146, 1156 y sS. Asimismo, desde una perspectiva crítica, PARDOLESI, R. "Clausole abusive, pardon vessatorie: verso l'attuazione di una direttiva abusata». Rivista critica del diritto privato, 1995, p. 527 y ss. (nota 15); id. "Clausole abusive (nei contratti con i consumatori): una direttiva abusata?». II Foro italiano, 1994, v, col. 146.

123 En tal sentido, si bien con diferencias puntuales de cierta importancia, véase lo que ya sostenía AzZARO, A. M. Op. cit., p. 97 y ss. Se debe negar, en cambio, que los artículos 1469-bis y ss. del Código Civil sean aplicables a aquellos contratos que, aun cuando unilateralmente predispuestos por un comerciante profesional, no son redactados mediante cláusulas generales, o sea, mediante cláusulas destinadas a regular una serie indefinida de relaciones contractuales. En efecto, cuando se trata de reglamentar específicamente una determinada relación contractual, la eventual asimetría informativa que sea desventajosa para la contraparte profesional no puede sino quedar a su cargo, porque no es imputable, en modo alguno, a la falencia del mercado, sino solamente a la eventual irracionalidad subjetiva con la cual dicha parte ejerce su propio poder de autonomía negocial. Dentro de estos límites, sacar provecho de las asimetrías informativas es coesencial al mecanismo del mercado y constituye, por lo demás, un incentivo irrenunciable para la creación de informaciones económicamente valorizables (véase, en general, GRUNDMANN, S. "La struttura del diritto europeo dei contratti». Op. cit., p. 395 y ss.).

124 LIBONATI, B. "Ordine giuridico e legge economica del mercato». Op. cit., p. 649 y ss.; LIPARI, N. «Il mercato: attività privata e regole giuridiche». Op. cit., p. 53; OPPO, G. "L'iniziativa economica». Op. cit., p. 328 y ss. Pero cfr., en sentido negativo, IRTI, N. L'ordine giuridico del mercato. Op. cit., passim, especialmente p. 16 y ss.

125 Atendiendo a este fundamento jurídico, justamente, se debe descartar que, contrariamente a lo que ha sostenido (si bien con cierta cautela) GATT; L. Op. cit., p. 838, la regulación aquí estudiada sea también aplicable "entre particulares o, por mejor decir, entre sujetos que actúan, por igual, con fines no profesionales». Dicha tesis, en tanto se esfuerza en asimilar forzosamente la intervención legislativa estudiada a la paridad formal entre los contratantes, traiciona su propia razón sustancial, la cual consiste, ni más ni menos, en la estructuración del mercado (véase retro, $n .{ }^{\circ}$ 2). En sentido crítico, y con respecto a semejantes operaciones culturales retrógradas, véase JANNARELL, A. Op. cit., p. 70. 
Al planteamiento que se acaba de exponer se podría objetar que el legislador italiano, con la inserción del artículo 1469-quinquies, 3. ${ }^{\circ}$ párrafo, del Código Civil, ha querido limitar la protección del adherente que actúe en el ámbito de su propia actividad profesional a una pretensión resarcitoria frente al predisponente; con ello, habría descartado, implícitamente, la conveniencia de un control de contenido, ${ }^{126}$ solo que tal objeción no parece convincente. Hay que destacar preliminarmente, en efecto, que el artículo 1469-quinquies, 3. ${ }^{\circ}$ párrafo, del Código Civil no es aplicable a todo profesional, sino, exclusivamente, al «vendedor», o sea, a aquel que enajena, a su vez, frente al consumidor, los bienes y servicios que ha adquirido del proveedor. La norma no concierne, desde un inicio, al comerciante profesional que se ubica en el segmento final del mercado (por ejemplo, al notario que adquiere una computadora para llevar la contabilidad de su notaría o al empresario constructor que adquiere un automóvil para el desarrollo de su propia actividad), respecto del cual, por ello, no podría valer el argumento a contrario. De manera más radical, cabe advertir que el artículo 1469-quinquies, 3. ${ }^{\circ}$ párrafo, del Código Civil no parece tener que ver con las cláusulas contractuales predispuestas por el comerciante profesional frente al vendedor, sino con aquellas predispuestas por el vendedor frente al cliente, bajo la imposición, o bien por mera recomendación, del proveedor. La declaratoria del carácter abusivo de tales cláusulas comporta la responsabilidad del proveedor frente al vendedor. Las cláusulas generales de contratación predispuestas por el comerciante profesional frente al vendedor son, por consiguiente, ajenas a la figura regulada por la norma, la cual no excluye indirectamente, entonces, el control de su contenido. ${ }^{127}$

Lo único cierto es que, cuando el adherente sea, precisamente, un comerciante profesional y no un consumidor, el fenómeno de la asimetría informativa entre las partes contratantes, a pesar de ser cualitativamente idéntico, puede ser menos intenso cuantitativamente, en particular en el caso de contratos que, si bien no susceptibles de ser considerados como «actos de la profesión", son, de todas maneras, habitualmente celebrados en ocasión del ejercicio de la profesión.

Atendiendo a esta diferencia de hecho, se debe descartar que se puedan aplicar, analógicamente, a los contratos entre empresarios las disposiciones del Código Civil en el que se identifican listas de cláusulas vejatorias, salvo prueba en contrario (arts. 1469 -bis, 3. ${ }^{\circ}$ párrafo, y 1469 -quinquies, $2 .^{\circ}$ pá-

126 Este argumento ha sido concebido (pero para cuestionar su carga concluyente) por BUSNELLI, F. D. "Una possibile traccia per una analisi sistematica della disciplina delle clausole abusive». En Commentario al capo XIV bis del codice civile: dei contratti del consumatore. Op. cit., p. 759.

127 SIRENA, P. "La nuova disciplina delle clausole abusive nei contratti stipulatti con i consumatori». Op. cit., p. 293. 
rrafo, del Código Civil): la tipificación de las cláusulas abusivas, en efecto, justamente por fundarse en el carácter estructural y no eliminable de la asimetría informativa, debería referirse solamente a los contratos entre un comerciante profesional y un consumidor.

Debe entenderse, además, que el juez, al evaluar la naturaleza abusiva de la cláusula, puede tomar en cuenta, como "circunstancia», en el sentido del artículo 1469 -ter, $10^{\circ}$ párrafo, del Código Civil, la experiencia profesional del adherente.

\section{Sigue: la modernización del derecho general del contrato y la de- manda de una recodificación}

Las consideraciones que hemos expuesto requieren una reflexión conclusiva sobre el futuro de las regulaciones de los contratos celebrados con los consumidores, que se identifica, en definitiva, con el futuro del derecho europeo de los contratos.

A corto plazo, es de auspiciar, desde luego, una revisión orgánica de la materia, destinada a eliminar defectos de redacción e incoherencias. Para ello, la consolidación de las distintas leyes especiales en un texto único o en un código del consumo constituye una obra bastante importante, la cual, por lo demás, encontrará alguna correspondencia con las iniciativas emprendidas por la Comunidad Europea para dar «mayor coherencia» al derecho europeo de los contratos. ${ }^{128}$

En cambio, si la observación se efectúa con un horizonte más amplio, dicha obra legislativa podría constituir solamente una estapa intermedia, ${ }^{129}$

128 Comunicación de la Comisión al Parlamento Europeo y al Consejo «Mayor coherencia en el derecho contractual europeo. Un plan de acción», 12 de febrero del 2003, COM (2003) 68 def.

El debate sobre las distintas opciones técnico-legislativas en juego está representado a plenitud por las ponencias recogidas en los volúmenes La riforma dei codici in Europa e il progetto di codice civile europeo. Editados por G. Alpa y E. N. Buccico. En Quaderni di rassegna forense. Consiglio Nazionale Forense. Milán, 2002; y GRUNDMANN, S y J. STUYCK (eds.). An Academic Green Paper on European Contract Law. La Haya, 2002. Igualmente, véase GAmbaro, A. "The Plan d'Action of the European Commission. A Comment». European Review of Private Law, 2003, p. 768 y ss.; StAUDENMAYER, D. "The Commision Action Plan on European Contract Law». European Review of Private Law, 2003, p. 113 y ss.; BAR, C. von y S. SWANN. "Response to the Action Plan on European Contract Law: A More Coherent European Contract Law (COM (2003) 63)». European Review of Private Law, 2003, p. 595 y ss. Véase también retro, $n .^{\circ} 1$.

129 Merecen ser citadas, por su contundencia y por ser de compartir, las palabras de ROPPO, V. Il contratto del duemila. Op. cit., p. 57: "Una obra semejante de consolidación (y autonomización) del cuerpo normativo concerniente a los contratos de los consumidores corre el riesgo de mirar hacia el pasado, porque tal categoría parece [...] superada». 
que antecede el logro de un objetivo más ambicioso: integrar, globalmente, las regulaciones de los contratos celebrados por los consumidores en el Código Civil. ${ }^{130}$

Desde el punto de vista ideal, esta segunda opción legislativa es claramente sugerida por el fundamento y por el significado sistemático de las regulaciones aquí analizadas: ellas, en efecto, y como hemos intentado demostrar, no concretizan la construcción de un derecho sectorial de los consumidores, sino que constituyen la más imponente modernización del derecho general de los contratos que se haya producido en el ordenamiento jurídico italiano desde la posguerra. ${ }^{131}$

Por más específico que pueda resultar el ámbito objetivo de aplicación de algunas de las normas en cuestión, ellas, vistas en su conjunto, han introducido en el ordenamiento jurídico un nuevo núcleo de principios generales, ${ }^{132}$ que es tarea del intérprete reconocer y valorizar, con una superación de los condicionamientos que derivan de la contingente topografía de las disposiciones legislativas. Empero, dicha reconstrucción conceptual de los datos normativos no puede dejar de reflejarse, recíprocamente, en el sistema de las fuentes del derecho, con lo cual se plantea el problema de una reforma de éste, que lo vuelva adecuado a la realidad sustancial del ordenamiento jurídico: la «descripción de las cosas» — como, autorizadamente, se ha sugerido— ${ }^{133}$ no coincide con la «lucha política», sino que llama, idealmente, a esta última.

130 Sobre la antítesis entre códigos y textos únicos, cfr., sin embargo, y en general, IRTI, N. L'età della decodificazione. 4. ${ }^{2}$ ed. Milán, 1999, p. 189 y ss.

131 Si el Código Civil es entendido como ley general del derecho privado (SCHLESINGER, P. "Codice civile e sistema civilistico: il nucleo codicistico e $i$ suoi satelliti». Rivista di diritto civile, 1993, I, p. 403 y ss.), constituye, por ende, la fuente del derecho más apropiada para la colocación de tales regulaciones.

132 MACARIO, F. "Alla ricerca dei "principi comuni» per l'armonizzazione del diritto europeo dei contratti». Op. cit., p. 30. Es significativo que, incluso si se rechazan soluciones basadas en la extensión del ámbito subjetivo de aplicación de las regulaciones que aquí se estudian, se haya planteado la interrogante sobre si la perspectiva de una "consumidorización» del derecho general de los contratos se pueda paragonar con la «mercantilización» del derecho general de los contratos, que fue realizada por el Código Civil de 1942 (JANNARELLI, A. Op. cit., p. 67 y ss.; ROPPO, V. «ll contratto». Op. cit., p. 929 y ss.). También sobre la base de la experiencia jurídica extranjera se ha advertido, en tal sentido, que las soluciones introducidas por las directivas comunitarias en la protección del consumidor tienden a ubicarse en el centro de la reglamentación de las relaciones privatísticas, de las cuales constituyen la nueva Gesetzrationalität (PATTI, S. "I contratti del consumatore e la ricodificazione tedesca». Op. cit., p. 518 y ss.). Para una evaluación decididamente negadora de dicha perspectiva, véase, en cambio, D'AMICO. "Regole di validità e di comportamento nella formazione del contratto». Op. cit., p. 48 y ss.; e, igualmente, MONATERI, P. G. Op. cit., p. 417, quien considera que los contratos entre empresas y consumidores (basados en el modelo del juego cooperativo) constituirían un paradigma jurídico parejamente alternativo al del contrato en general (basado en el modelo del juego antagónico).

133 IRTI, N. L'età della decodificazione. Op. cit., p. 12 y ss. 
En relación con la alternativa entre Código Civil y leyes especiales, la colocación de las regulaciones examinadas no constituye un accidente exterior y, por decirlo así, «neutral». ${ }^{134}$ Ella coadyuva, decididamente, a determinar el papel paradigmático de tales regulaciones respecto del ordenamiento jurídico considerado en su conjunto y a guiar, así, su evolución. ${ }^{135}$ Por ello, para que las reglas en mención puedan desplegarse en toda su potencialidad expansiva, es necesario que participen de aquella "plusvalía política» que aún hoy se reconoce, con buena disposición, al Código Civil, ${ }^{136}$ con lo cual se reconfirma el significado de este como estructura central del ordenamiento en su rama privatística. ${ }^{137}$

No es dado objetar que algunas de las regulaciones examinadas (sobre las cláusulas abusivas y sobre la venta) ya están previstas en el Código Civil, porque ellas no han sido integradas, orgánicamente, en el régimen codificado del contrato y parecen constituir, más bien, cuerpos separados y postizos de disposiciones. Así pues, aun cuando ubicadas al interior del Código Civil, se puede continuar considerándolas, paradójicamente, como leyes especiales. ${ }^{138}$

En realidad, y de acuerdo con lo que ya hemos destacado, ${ }^{139}$ se puede identificar en las regulaciones de los contratos celebrados con los consumidores una parte especial, cuya exigencia de ser ubicada en el interior del Código Civil no sería indudable si este último, en tanto custodio del derecho

134 Así se descarta, paradójicamente, el razonamiento de WILHELMSSON, T. "Is There a European Consumer Law - and Should There Be One?». Op. cit., p. 3.

135 Para un amplio estudio crítico de las diversas opciones de técnica legislativa, véase ROTH, W.-H., "Europäischer Verbraucherschutz und BGB». En Juristenzeitung, 2001, p. 475 y ss.

136 IRTI, N. Codice civile e società politica. Roma, Bari, 1995, p. 5 y ss.

137 CIAN, G. "Significato e lineamenti della riforma dello Schuldrecht tedesco». Op. cit., p. 18. Para una radical reconsideración de dicha idea, entendida, en clave posmoderna, no ya como asimilación de las diferencias, sino como creación de un vocabulario común y de un «marco» en el cual se confrontan las diferencias, véase CAPPELLINI. "II codice eterno. La Forma-Codice e i suoi destinatari: morfologie e metamorfosi di un paradigma della modernità». En P. Cappellini y B. Sordi (eds). Codici. Una riflessione di fine millennio. Actas del encuentro académico celebrado en Florencia del 26 al 28 de octubre del 2000. Milán, p. 11 y ss., especialmente 64 y ss.; cfr., igualmente, CAPRIOLI, S. "Codice (abbozzo di una voce per un dizionario di diritto privato)». Rivista trimestrale di diritto e procedura civile, 2003, p. 379 y ss.

138 Según PATTI, S. "I contratti del consumatore e la ricodificazione tedesca». Op. cit., $p$. 506, es posible hablar, por lo tanto, de una codificación meramente formal, que se ha limitado a insertar algunos nuevos artículos en el Código Civil, pero sin integrarlos orgánicamente en el sistema conceptual y normativo de este (contrariamente a la llamada große Lösung que, si bien con ciertos límites, ha tenido lugar en el derecho alemán, con la reciente reforma orgánica del BGB). 
privado general, tuviera que «limitarse» a salvaguardar los valores esenciales de tal derecho. ${ }^{140}$ En tal sentido, y por ejemplo, resulta probablemente indiferente ( $\mathrm{y}$ preferible, es más) que las disposiciones en materia de crédito al consumo sean dictadas no por el Código Civil, sino por el texto único en materia bancaria y crediticia.

No se puede ocultar que, desde la perspectiva trazada, el Código Civil resultaría (ulteriormente) "contaminado" por disposiciones legislativas ajenas a su diseño original, además de escritas en un lenguaje inevitablemente distinto de aquel, nítido y pacato, que sus artífices pudieron adoptar hacia la mitad del siglo XX.

Con todo, y habiéndose superado la ambición de completitud y de inmutabilidad que caracterizaba la idea de código civil en la edad del positivismo decimonónico, ${ }^{141}$ lo que está ante nosotros es un paso necesario para que el Código, más allá de la nostalgia de pensamiento de los juristas, reafirme su propia y perdurable vitalidad, entendida, en palabras egregiamente pronunciadas, como "capacidad de reflejar jurídicamente aquel substrato de valores sustanciales en el que se basa la cultura de la sociedad». ${ }^{142}$

140 IRTI, N. L'età della decodificazione. Op. cit., p. 12.

141 SACCO, R. «I codici civili dell'ultimo cinquantennio». Rivista di diritto civile, 1993, I, p. 311 y ss.; y, desde el punto de vista histórico, GROSSI, P. "Codici: qualche conclusione tra un millennio e l'altro». En Codici. Una riflessione di fine millennio. Op. cit., p. 579 y ss.

142 FALZEA. "A chiusura delle celebrazioni cinquantenarie del codice civile». Rivista di diritto civile, 1993, I, p. 217. 